\title{
Cynthia Savioli
}

\section{Características orofaciais de pacientes com artrite idiopática juvenil}

\author{
Dissertação apresentada ao Programa de Pós- \\ graduação em Fisiopatologia Experimental da \\ Faculdade de Medicina da Universidade de São \\ Paulo para obtenção do título de Mestre em \\ Ciências
}

Área de concentração: Fisiopatologia Experimental Orientador: Dr. José Tadeu Tesseroli de Siqueira

São Paulo

2005 


\section{Cynthia Savioli}

\section{Características orofaciais de pacientes com artrite idiopática juvenil}

Dissertação apresentada ao Programa de Pósgraduação em Fisiopatologia Experimental da Faculdade de Medicina da Universidade de São Paulo para obtenção do título de Mestre em Ciências

Área de concentração: Fisiopatologia Experimental Orientador: Dr. José Tadeu Tesseroli de Siqueira

São Paulo

2005 
Aos meus pais, Mário e Olga Marli e aos meus irmãos Márcio e Vinicius pelo incentivo e apoio de todas as horas;

Ao meu marido Rodrigo, por todo amor, paciência e companheirismo;

Aos pacientes com artrite idiopática juvenil, suas necessidades me motivaram a estudá-los e a força de vontade, determinação e alegria destes pacientes fizeram com que eu jamais desanimasse. 


\section{AGRADECIMENTOS}

Ao Dr José Tadeu Tesseroli de Siqueira, meu orientador e exemplo de dedicação, ética, sabedoria... Obrigada por sua orientação e por ter me mostrado de uma forma realista, a verdadeira beleza e importância de nossa profissão. Observando-o, entendi o que é ser professor;

Ao $\operatorname{Dr}$ Clovis Artur Almeida da Silva pelo incentivo, motivação, empenho e imensa contribuição neste trabalho;

Aos assistentes, aprimorandos e funcionários da Divisão de Odontologia, pela ajuda e amizade;

Aos assistentes e residentes da Unidade de Reumatologia Pediátrica, pela atenção e ensinamentos oferecidos;

A Dra Maria Estela Justamante de Farias, Dr Fernando Vasconcelos e Dra Terezinha Amaral pela grande colaboração;

Aos amigos Dra Eliane, Maria Estela, Reynaldo, Júnior, Jorge, Silvia, Fábio, Gisele, Cinara, Alessandra Duarte, Heloísa Dias e Andréa Dário pela ajuda e paciência nos momentos de lamentação;

Ao Flávio, Flávia, Ceci, Teco, Adriana, Pierre e Carla pela amizade presente em todas as horas.

A todos, muito obrigada! 
Esta dissertação está de acordo com:

Referências: adaptado de International Committee of Medical Journals Editors (Vancouver)

Universidade de São Paulo. Faculdade de Medicina. Serviço de Biblioteca e Documentação. Guia de apresentação de dissertações, teses e monografias. Elaborado por Annelise Carneiro da Cunha, Maria Julia de A L Freddi, Maria F Crestana, Marinalva de Souza Aragão, Suely Campos Cardoso, Valéria Vilhena. São Paulo: Serviço de Biblioteca e Documentação; 2004.

Abreviaturas dos títulos dos periódicos de acordo com List of Journals Indexed in Index Medicus 


\section{SUMÁRIO}

Lista de siglas

Lista de tabelas

Resumo

Summary

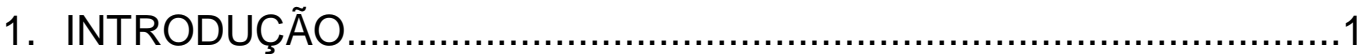

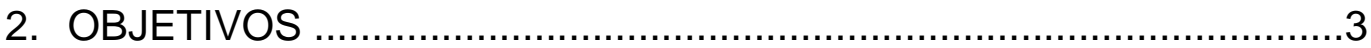

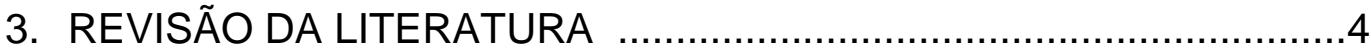

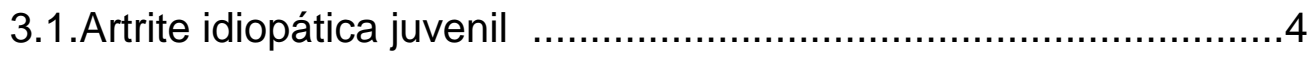

3.2.Sistema estomatognático. ................................................... 16

3.3. Crescimento facial em pacientes com AlJ .............................24

3.4. Disfunção temporomandibular em pacientes com AlJ................30

3.5.Considerações dentais e periodontais em pacientes com AlJ ....36

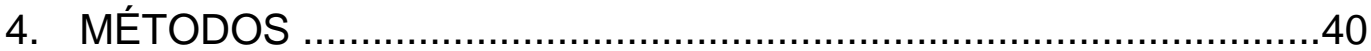

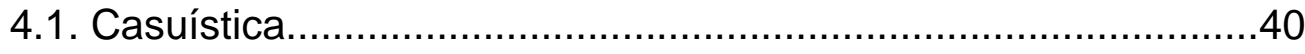

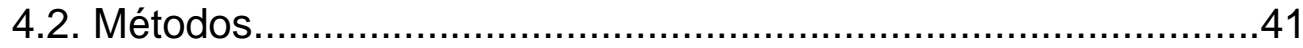

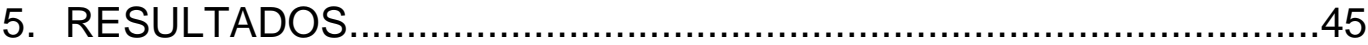

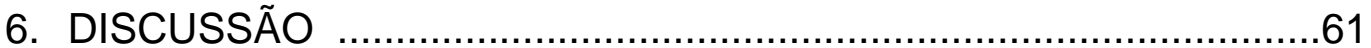

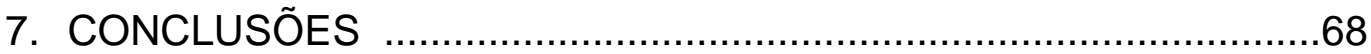

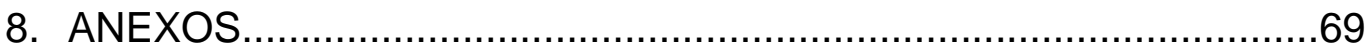

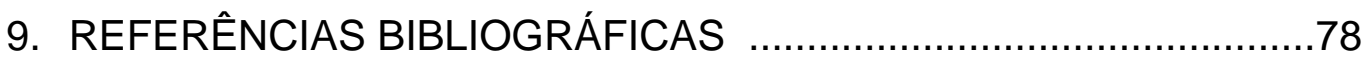




$\begin{array}{ll}\text { AIJ } & \text { Artrite idiopática juvenil } \\ \text { AINH } & \text { Antiinflamatórios não hormonais } \\ \text { ATM } & \text { Articulação temporomandibular } \\ \text { CI } & \text { Classe } \\ \text { dp } & \text { Desvio padrão } \\ \text { DTM } & \text { Disfunção temporomandibular } \\ \text { FAN } & \text { Fator anti-núcleo } \\ \text { FR } & \text { Fator reumatóide } \\ \text { IDC } & \text { Índice de disfunção clínica } \\ \text { IMM } & \text { Índice de mobilidade mandibular } \\ \text { IP } & \text { Índice de placa } \\ \text { IS } & \text { Índice de sangramento gengival } \\ \text { OC } & \text { Oclusão Central } \\ \text { RC } & \text { Relação Central } \\ \text { VHS } & \text { Velocidade de hemossedimentação }\end{array}$




\section{LISTA DE TABELAS}

Tabela 1: Distribuição dos grupos quanto ao sexo e à idade. .45

Tabela 2: Comprometimento das articulações do corpo e características clínicas do grupo com AlJ .46

Tabela 3: Medicações em uso pelos pacientes com AlJ. 47

Tabela 4: Distribuição dos grupos quanto à presença de queixas na região orofacial

Tabela 5: Distribuição dos grupos quanto à relação molar e ao perfil facial.

Tabela 6: Distribuição dos grupos quanto à presença de mordida aberta anterior 50

Tabela 7: Distribuição dos grupos quanto às características dentárias e gengivais.

Tabela 8: Distribuição dos doentes com AlJ de acordo com o número de articulações comprometidas dos membros superiores e sua relação com os índices de saúde oral, comparativamente ao grupo controle. .52

Tabela 9: Distribuição dos grupos quanto aos Índices de Helkimo (Disfunção Clínica e Mobilidade Mandibular) .53

Tabela 10: Amplitude dos movimentos mandibulares dos pacientes com AlJ, comparativamente aos controles .54 
Tabela 11: Distribuição dos grupos quanto à presença de dor nos músculos da mastigação (muscular), na articulação temporomandibular

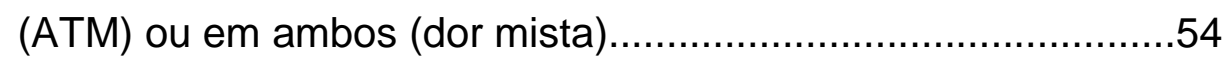

Tabela 12: Distribuição dos doentes com AIJ relacionando o tipo de perfil facial e os Índices de Disfunção de Helkimo com a idade de início e o tempo de duração da AlJ. .55

Tabela 13: Distribuição dos grupos quanto à presença de ruídos na ATM.. 56 Tabela 14: Distribuição dos grupos quanto ao grau de alteração radiográfica condilar realizado por 4 examinadores independentes. .57

Tabela 15: Distribuição dos grupos quanto à concordância entre 2 de 4 examinadores sobre a presença de alterações condilares nas radiografias panorâmicas.

Tabela 16: Distribuição dos grupos quanto à coincidência entre os examinadores sobre a presença de alterações condilares nas radiografias panorâmicas. .58

Tabela 17: Distribuição dos grupos quanto ao grau de alterações $\begin{array}{llllll}\text { radiográficas } & \text { condilares } & \text { por } & 3 & \text { de } & 4\end{array}$ examinadores. .59

Tabela 18: Distribuição dos grupos quanto à presença de alterações radiográficas condilares subdivididas em 2 graus de comprometimento 60 


\section{RESUMO}

Savioli C. Características orofaciais de pacientes com artrite idiopática juvenil [dissertação]. São Paulo: Faculdade de Medicina, Universidade de São Paulo; 2005. 91p.

A artrite idiopática juvenil frequentemente afeta a articulação temporomandibular, compromete o crescimento facial e pode ser fator de risco para cáries e doenças periodontais. Entretanto, são escassos os estudos que avaliam em conjunto todas essas alterações. $\mathrm{O}$ objetivo deste estudo foi avaliar a condição dentária, as características faciais e a articulação temporomandibular de 35 pacientes com artrite idiopática juvenil, evolução poliarticular, tratados em hospital escola, comparativamente a um grupo controle de 35 crianças saudáveis. O estudo constou de avaliação sistemática das estruturas dentárias, orais e faciais através de: questionário de anamnese, índice CPO-D, índice de placa, índice de sangramento gengival, relação dentária, perfil facial, índice de Helkimo e classificação das alterações condilares observadas nas radiografias panorâmicas da face. A idade média foi de $11,4 \pm 3,47$ e 10,4 $\pm 2,56$ anos, respectivamente para os grupos estudo e controle. No grupo com artrite idiopática juvenil estiveram significativamente presentes, comparativamente ao grupo controle: o perfil facial convexo $(p=0,002)$; os ruídos articulares $(p=0,040)$; a disfunção da articulação temporomandibular ( $p=0,003)$; a limitação da abertura bucal $(p=0,001)$, a mobilidade mandibular gravemente comprometida $(p=0,001)$ e a dor à palpação articular e dos músculos da mastigação $(p=0,001)$. $O$ índice CPO-D dos pacientes com artrite idiopática juvenil com 3 a 8 articulações de membros superiores comprometidas pela doença foi estatisticamente diferente que $o$ do grupo controle $(p=0,036)$, no entanto os índices de placa e de sangramento gengival, em números absolutos foram maiores no grupo com artrite idiopática juvenil, embora sem diferenças estatisticamente significativas, havendo aumento progressivo desses índices à medida que aumentaram 0 número de articulações de membros superiores comprometidas pela artrite idiopática juvenil. Ao exame radiográfico a prevalência da alteração do côndilo mandibular foi estatisticamente diferente no grupo com artrite idiopática juvenil $(p=0,041)$, sendo de grau 2 as alterações mais freqüentes $(p=0,010)$. Este estudo mostrou que os pacientes com artrite idiopática juvenil avaliados têm alterações faciais e mandibulares graves, que podem ser atribuídas aos efeitos diretos da doença na articulação temporomandibular. Por outro lado, a maior freqüência de doenças dentárias e gengivais que apresentaram pode ser atribuída, em parte, como efeito secundário da artrite idiopática juvenil na saúde oral.

Descritores: Artrite reumatóide juvenil, sistema estomatognático, articulação temporomandibular, boca, face. 


\section{SUMMARY}

Savioli C. Dental and facial characteristics of patients with juvenile idiopathic arthritis [thesis]. São Paulo: "Faculdade de Medicina, Universidade de São Paulo"; 2005. 91p.

The juvenile idiopathic arthritis frequently affects the temporomandibular joint, compromises the facial growth and can be factor of risk to tooth decay and gingival diseases. However, there are few studies that correlate all those alterations. The aim of this study was to evaluate the dental condition, facial characteristics and the temporomandibular joint of the 35 patients with juvenile idiopathic arthritis treated in a large teaching hospital, comparatively with a control group of 35 healthy children. The study consisted of systematic evaluation of their dental, oral, and facial structures, through: anamnesis questionnaire, DMFT index, plaque and gingival bleeding index, dental relationship, facial profile, Helkimo's index and classification of condilar alterations observed in ortopanthomography. The mean age was $11.4 \pm 3.47$ and $10.4 \pm 2.56$ years, respectively to the study group and control group. In the juvenile idiopathic arthritis group were significantly presents, comparatively with a control group: the convex facial profile $(p=0.002)$; joint noise $(p=0.040)$, temporomandibular joint dysfunction $(p=0.003)$; limited of mouth opening $(p=0.001)$; mandibular mobility severely impaired $(p=0.001)$ and the articular and masticatory muscles palpation pain $(p=0.001)$. The DMFT index of juvenile idiopathic arthritis patients with 3 to 8 affected joints in superior limbs, was statistically different that control group $(p=0.036)$, however the plaque and gingival bleeding indexes, were higher in juvenile idiopathic arthritis group, although without statistically significant difference, with progressive increase in these index, in proportion to a higher number of superior limbs joints involved by juvenile idiopathic arthritis. In accordance with the radiographic evaluation, the incidence of condilar alteration was statistically different in juvenile idiopathic arthritis group $(p=0.041)$, and the grade 2 was the most frequent alterations $(p=0.010)$. This study showed that the patients with juvenile idiopathic arthritis evaluated have severe facial and mandibular alterations what can be a direct effect of the disease in the temporomandibular joint. And also, the higher frequency of dental and gingival diseases can be considered, as a secondary effect of juvenile idiopathic arthritis on oral health.

KEY WORDS: Juvenile rheumatoid arthritis, stomatognathic system, temporomandibular joint, mouth, face. 



\section{INTRODUÇÃO}

Artrite idiopática juvenil é uma doença sistêmica, imunoinflamatória crônica, com início antes dos 16 anos de idade e que afeta uma ou mais articulações do corpo ${ }^{1}$.

O envolvimento do sistema mastigatório, principalmente o comprometimento da articulação temporomandibular (ATM) por esta doença reumatológica é muito comum. Inflamação crônica nesta articulação resulta em alterações degenerativas e na presença de sinais e sintomas de disfunção, como dor, ruídos articulares e limitação do movimento ${ }^{2}$. Alterações no crescimento facial, como micrognatia, retrognatia, má oclusão e mordida aberta anterior, também podem ocorrer em decorrência do envolvimento condilar ${ }^{3,4,5}$. As alterações condilares são freqüentes ${ }^{6,7}$ e os sinais de envolvimento da ATM excedem os sintomas clínicos, podendo os pacientes ser assintomáticos mesmo com a presença de graves alterações na ATM $^{8,9}$, por isto a avaliação periódica com radiografia panorâmica é recomendada para todas as crianças com AlJ ${ }^{2}$.

Os dentes e a gengiva podem ser indiretamente afetados pela AIJ, em razão da terapia medicamentosa utilizada para o controle da doença, pelo próprio acometimento da articulação temporomandibular e principalmente pelo comprometimento de membros superiores, dificultando a realização de adequada higiene oral, contribuindo assim para maior prevalência de doenças dentárias e periodontais ${ }^{10,11,12}$ 
O acometimento do sistema mastigatório é mais freqüente e mais grave nos pacientes com AIJ na forma evolutiva poliarticular ${ }^{13}$, o que justifica a necessidade de avaliação dentária e maxilo-mandibular desses pacientes com a finalidade de conhecer suas características orofaciais e de implementar medidas diagnósticas ou terapêuticas adequadas no âmbito da odontologia. Dessa forma é possível prevenir o risco das doenças infecciosas dentárias e gengivais, reduzindo seu risco potencial sobre a própria doença reumatológica. Da mesma forma, as anormalidades na ATM decorrentes da AlJ, devem ser melhor compreendidas para adoção de medidas preventivas ou de tratamentos que reduzam, no segmento facial, as seqüelas dessa doença e contribuam para melhora da qualidade de vida destas crianças. 


\section{OBJETIVOS}

Este estudo de caso controle tem por objetivo avaliar aspectos odontológicos e a ATM das crianças com artrite idiopática juvenil forma evolutiva poliarticular, comparativamente a um grupo controle, avaliando:

1. Prevalência de doenças dentárias e periodontais;

2. Prevalência de disfunção mandibular (ATM);

3. Características oclusais;

4. Perfil facial;

5. Presença de alterações radiográficas na ATM;

6. Relação das características orofaciais com a doença. 


\section{REVISÃO DA LITERATURA}

\subsection{ARTRITE IDIOPÁTICA JUVENIL (AIJ)}

\subsubsection{Histórico}

A primeira descrição de AlJ foi configurada, possivelmente, em 1608, por um artista, Caravaggio, que em uma pintura intitulada "Il Amore Dormiente", retratou uma criança do sexo masculino com poliartrite crônica, caracterizada por comprometimento da coluna cervical, hipodesenvolvimento da mandíbula, sugestivo de comprometimento das articulações temporomandibulares e aumento do volume dos cotovelos, dos joelhos e das articulações interfalangeanas proximais das mãos ${ }^{14}$.

O primeiro médico a descrever AIJ foi Cornil (1864), citado por Oliveira $(2001)^{15}$ relatando uma paciente de 12 anos de idade com poliartrite, que evoluiu com cronicidade do processo inflamatório com óbito aos 29 anos de idade.

Em 1889, um médico brasileiro, Dr Carlos Artur Moncorvo de Figueiredo fez uma revisão de 8 casos de AlJ e descreveu mais um sobre o assunto [Moncorvo (1880) ${ }^{\boxplus}$ citado por Oliveira(2001)] ${ }^{15}$.

\footnotetext{
${ }^{I}$ Cornil MV. Mémoire sur lês coincidences pathologiques du rhumatisme articulaire chronique. Comptes rendus séances et mémoires de la Société de Biologie, 1864.

${ }^{\text {II }}$ Moncorvo. Du rhumatisme chronique noueux dês enfants. Paris, 1880.
} 


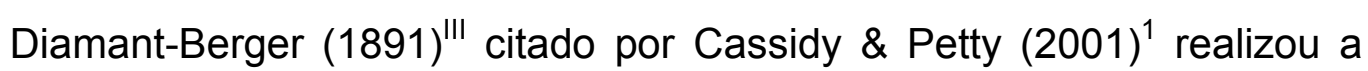
primeira grande revisão sobre as artrites crônicas, descrevendo 3 casos pessoais e revisando outros 35 publicados anteriormente, salientando o início agudo da doença, o acometimento predominante de grandes articulações, o curso caracterizado por exacerbações e remissões, os freqüentes distúrbios do crescimento e um prognóstico geralmente bom .

Still (1896) $)^{\mathbb{N}}$ citado por Brewer $(1994)^{16}$ publicou uma descrição detalhada de AIJ, com predomínio de manifestações sistêmicas. Distinguiu três grupos de pacientes, sugerindo que a artrite crônica na criança pode incluir mais que uma doença. Atualmente essa sua descrição é considerada clássica para AlJ, forma sistêmica.

\subsubsection{Nomenclatura}

O termo Artrite Idiopática Juvenil foi proposto em 1993 na tentativa de se estabelecer uma melhor denominação para esta doença, até então conhecida por Artrite Reumatóide Juvenil (ARJ) e Artrite Crônica Juvenil $(A C J)$. Alguns autores acreditam que o termo reumatóide não é adequado, pois menos de $10 \%$ das crianças tem um padrão de doença que se assemelhe a Artrite Reumatóide do adulto. Por outro lado, o termo crônico parece exagerado, pois a doença tem evolução imprevisível e muitas vezes com curso benigno, sem limitação da vida cotidiana. Este termo crônico

\footnotetext{
III Diamant-Berger MS. Du rhumatisme noueux (polyarthrite déformante) chez les enfants. Paris: le Cros Nier et Babe, édit, 1891, pp1480.

IV Still GF. A form of chronic joint disease in children. Br Med J 1896; 2:1446
} 
também pode estigmatizar, com conseqüente impacto psicológico sobre a criança e a família ${ }^{17}$. Outras denominações como doença de Still, e artrite juvenil permanecem em uso pela literatura médica ${ }^{18}$.

\subsubsection{Critérios Gerais para Diagnóstico}

Alguns critérios foram propostos por diferentes entidades para tentar classificar artrite crônica na criança.

O critério proposto pelo "American College of Rheumatology" (ACR), publicado em 1972 e modificado em 1977, define como ARJ, a artrite que afeta uma ou mais articulações na criança até 16 anos, por no mínimo seis semanas. Conforme o predomínio clínico nos seis primeiros meses, classifica a doença em três tipos de início (pauciarticular, poliarticular e sistêmico) e é necessário a exclusão de outras doenças reumáticas, como espondiloartropatias soronegativas ${ }^{19,20}$.

A Liga Européia contra o Reumatismo (EULAR) em 1977 propôs o termo Artrite Crônica Juvenil (ACJ), restringindo o termo ARJ ao grupo de início poliarticular com fator reumatóide positivo. Este diagnóstico requer início antes dos 16 anos de idade e tempo mínimo de artrite de três meses e inclui as espondiloartropatias. Exclui outras doenças que causam artrites, tais como doenças infecciosas e hematológicas, entre outras ${ }^{20}$.

Em 1993, o Comitê Pediátrico Permanente da Liga Internacional da Associação de Reumatologia (ILAR) propôs uma nova classificação, sugerindo o termo Artrite Idiopática Juvenil (AIJ), definindo-a como artrite 
crônica manifestada antes dos 16 anos, com evolução mínima de 6 semanas. Classifica a doença em sete categorias: artrite sistêmica, oligoartrite (persistente ou estendida), poliartrite fator reumatóide positivo, poliartrite fator reumatóide negativo, artrite psoriática, artrite associada a entesites e artrites indiferenciadas ${ }^{17,20,21,22 .}$

\subsubsection{Classificação}

Quanto às formas de início, pode ser classificada em:

a) Sistêmica:

Ocorre em 10 a $15 \%$ das crianças com AlJ, sem predomínio de sexo e em qualquer faixa etária ${ }^{1,23,24}$. Caracteriza-se pela presença de febre diária, intermitente, muitas vezes acompanhada por exantema reumatóide, podendo ter outros envolvimentos viscerais como hepatomegalia, linfadenopatia, esplenomegalia, comprometimento cardíaco (pericardite e miocardite), comprometimento pulmonar (pleurite e pneumonite), e estas podem preceder as manifestações articulares em semanas, meses ou anos, porém a presença de artrite é obrigatória para o diagnóstico de AlJ. O comprometimento ocular (iridociclite crônica ou uveíte anterior) é excepcionalmente evidenciado nessa forma de início ${ }^{1}$.

b) Poliarticular:

Presença de artrite em cinco ou mais articulações durante os primeiros seis meses de doença ${ }^{1}$. Ocorre em 30 a $40 \%$ das crianças com AlJ, sendo aproximadamente $75 \%$ destes pacientes do sexo feminino, com pico de 
início de um a três anos e oito a 10 anos ${ }^{24}$. Apresenta-se com poucos sinais e sintomas sistêmicos, sendo comum fadiga, febre baixa e anemia. Caracteriza-se por artrites simétricas envolvendo grandes e pequenas articulações ${ }^{1,23,24}$. Distinguem-se dois subtipos:

- Poliartrite fator reumatóide negativo: compreende aproximadamente $20 \%$ das crianças com AlJ com artrite crônica em mais de quatro articulações, em que não se detecta o fator reumatóide. Predomina no sexo feminino (3:1) e pode acometer qualquer faixa etária ${ }^{23}$.

- Poliartrite fator reumatóide positivo: é a forma de menor incidência, apenas $5 \%$ das $\mathrm{AlJ}^{23}$. Na grande maioria, a doença se inicia entre 12 e 16 anos e cerca de $90 \%$ dos pacientes pertencem ao sexo feminino. Compreende os casos com mais de quatro articulações comprometidas e que se detecta positividade do fator reumatóide. É muito semelhante à Artrite Reumatóide do adulto ${ }^{1,23}$.

c) Oligoarticular:

É o subtipo mais comum, representa 40 a $50 \%$ dos casos de $\mathrm{AlJ}^{23}$ e se caracteriza pela presença de artrite crônica em uma a quatro articulações ${ }^{25}$, manifestações sistêmicas são raras exceto pelo comprometimento oftalmológico, com uveíte associada em $20 \%$ dos casos ${ }^{1}$. Há predomínio do sexo feminino e o pico de incidência é em torno de 1 a 3 anos de idade. Subdivide-se em:

- Oligoarticular persistente: persiste com até quatro articulações envolvidas após os primeiros seis meses de doença ${ }^{24}$ 
- Oligoarticular estendida: compreende 20 a $30 \%$ da forma oligoarticular e caracteriza-se pelo envolvimento de mais de quatro articulações após os primeiros seis meses de doença, seguindo um curso poliarticular ${ }^{23}$.

d) Artrite relacionada a entesites:

Constitui cerca de $10 \%$ dos casos de AlJ. Afeta principalmente o sexo masculino com idade superior a oito anos. Caracteriza-se pelo envolvimento de articulações periféricas, geralmente oligoarticular e assimétricas, entesites (inflamação das estruturas que se inserem ao osso) e outras características semelhantes às observadas nas espondiloartropatias e forte associação com o HLA-B27 ${ }^{23}$.

e) Artrite Psoriática

Esta é definida pela presença de artrite e psoríase ou artrite e duas das seguintes: dactilite, onicólise (unha em dedal) e presença de psoríase em parente de primeiro grau ${ }^{1,21}$. A artrite precede um diagnóstico de psoríase em $40 \%$ a $50 \%$ das crianças com diagnóstico de artrite psoriática ${ }^{24}$.

f) Artrite indiferenciada

Quando a artrite não preenche características das artrites acima ou preenche duas ou mais características acima.

\subsubsection{Epidemiologia}


Os estudos epidemiológicos mostram resultados diferentes, provavelmente em razão da heterogeneidade da doença, diferenças na aplicação dos critérios diagnósticos e falta de uniformidade nas pesquisas ${ }^{15}$.

É uma doença de incidência variada, 9,2 a 54,6/100.000 habitantes ${ }^{26}$, assim como a prevalência (8 a 202/100.000 habitantes) ${ }^{15}$. É mais freqüente no sexo feminino nas formas pauciarticular e poliarticular, não havendo diferença na forma sistêmica ${ }^{27}$. A Unidade de Reumatologia Pediátrica do Instituto da Criança do Hospital das Clínicas da Faculdade de Medicina da Universidade de São Paulo registra desde 1984, uma média de 10 a 12 casos novos por ano ${ }^{28}$.

Em relação à idade de início, tem um pico de maior freqüência em crianças com menos de cinco anos e de 10 a 16 anos ${ }^{15}$.

\subsubsection{Etiopatogenia}

A etiologia precisa da AlJ e os mecanismos patogênicos iniciais ainda não estão bem definidos. Supõe-se que a etiologia deva ser múltipla e os mecanismos patogênicos variados, entre os diferentes tipos da doença ${ }^{15}$.

Acredita-se que a doença tenha uma base imunológica pelas evidências de imunidade alterada, imunorregulação anormal e produção de citocinas (com expressões aumentadas de IL-6, IL-1 e TNF $\alpha$ no início sistêmico; IL-1 $\alpha$ no sangue, IL-1 $\beta$ no líquido sinovial e TNF $\alpha$ em ambos, nas formas de início poliarticular e oligoarticular) ${ }^{1}$. Pouco se sabe sobre os mecanismos que levam a quebra de tolerância e a doenças auto-imunes 
como a AIJ, mas suspeita-se que a homeostasia dos sistemas imunológico e neuroendócrino seria rompida por fatores externos (infecções, traumas e fatores psicológicos) em indivíduos geneticamente susceptíveis (especificamente por alterações das moléculas do sistema HLA) ${ }^{1,15,24}$.

O processo patológico pode ocorrer em qualquer articulação com membrana sinovial. Acredita-se que um "antígeno" desequilibraria a estrutura desencadeando um processo inflamatório. O sistema imunológico seria ativado, os linfócitos T (CD4) reconheceriam "antígenos" na articulação e ativaria células plasmáticas, fibroblastos, mastócitos e macrófagos, com produção de citocinas e óxido nítrico, ocorrendo morte celular, neovascularização e formação do "pannus" (hipertrofia de células sinoviais, fibroblastos e vasos sanguíneos com infiltração celular de linfócitos, macrófagos, mastócitos, células dendríticas, plamócitos, eosinófilos, neutrófilos e imunocomplexos). O "pannus" gradualmente se estende sobre a superfície articular e enzimas sintetizadas por células deste tecido destroem a cartilagem e osso subcondral. Desde o início do processo, condrócitos estimulados produzem citocinas (IL-1 e prostaglandinas) e enzimas, que contribuem para a destruição da cartilagem e facilitam a invasão do "pannus". A metaplasia deste tecido de granulação pode resultar na formação de nova cartilagem, osso ou tecido fibroso, resultando em deformidades e até anquilose óssea ${ }^{1,29,30}$. 


\subsubsection{Características Clínicas e Radiográficas}

Como características clínicas temos:

- Manifestações articulares: eritema, calor, edema, dor à palpação e aos movimentos, diminuição da mobilidade, crepitação e atrofia muscular ${ }^{16,31}$. A artrite pode envolver qualquer articulação, podendo ocorrer com espessamento sinovial significativo, podendo ou não ocorrer aumento de volume articular, mas com progressiva restrição de movimentos, provocando dor de intensidade variável ${ }^{23}$. A queixa de dor nem sempre é expressa verbalmente, parece depender da idade de desenvolvimento da criança, porém muitas vezes pode ser expressa por irritabilidade aumentada, articulações com dor a palpação, dor a mobilização e limitação de movimento ${ }^{1}$.

- Manifestações sistêmicas: febre, exantema, nódulos subcutâneos, fadiga, anorexia, manifestações cardíacas (pericardite e miocardite), iridociclite, linfadenopatia, hepatomegalia, esplenomegalia e alterações

renais ${ }^{16}$. Algumas crianças, principalmente com a forma sistêmica e poliarticular da AlJ, apresentam comprometimento pondo-estatural, com desnutrição protéico-calórica e baixa estatura, quando comparadas a uma população controle ${ }^{32}$. As causas da baixa estatura são multifatoriais incluindo: atividade prolongada da doença, anorexia, imobilização prolongada, destruição epifisiária com fechamento precoce da cartilagem de crescimento, uso crônico de medicamentos, osteoporose ${ }^{33}$ e dificuldade de mastigação em decorrência do comprometimento da ATM ${ }^{34}$. 
As alterações radiológicas inicialmente consistem em edema de partes moles, aumento do espaço articular e osteoporose periarticular. Em casos mais avançados observa-se destruição da cartilagem articular com diminuição concomitante do espaço articular, presença de cistos ósseos, erosões periarticulares e anquilose, com destruição articular completa ${ }^{31}$.

\subsubsection{Achados Laboratoriais}

Nos exames laboratoriais, freqüentemente, são achados anemia (hemoglobina abaixo de $10 \mathrm{~g} / \mathrm{dl}$ ), tendo sido observada em todos os sistêmicos, $78 \%$ dos poliarticulares e $42 \%$ dos oligoarticulares, plaquetose (plaquetas acima de $400.000 / \mathrm{mm}^{3}$ ) e leucocitose (leucócitos acima de 12.000/ $\mathrm{mm}^{3}$ ) em razão da intensa atividade inflamatória. Estas alterações apresentam valores moderados nas formas poliarticulares e discretos ou normais nas oligoarticulares. Além da inflamação, o uso de corticosteróides também pode ser responsável pela leucocitose. A velocidade de hemossedimentação (VHS) acima de $20 \mathrm{~mm} / 1^{\text {a }}$ hora é um indicador de atividade inflamatória inicial e evolutivo, podendo refletir uma atividade subclínica. A VHS elevada confirma inflamação, no entanto os valores normais não excluem a presença de condições inflamatórias. O fator reumatóide (FR) está positivo em 10 a $20 \%$ das crianças com AlJ, habitualmente na forma poliarticular com cursos mais graves de doença ${ }^{1,16,35}$. 


\subsubsection{Tratamento}

O tratamento da AlJ consiste em controlar as manifestações clínicas da doença, preservar a função articular e prevenir deformidades, através de terapêutica medicamentosa e multidisciplinar ${ }^{16,36}$.

Os medicamentos utilizados são:

- Antiinflamatórios não hormonais (AINH):

Este grupo de medicamentos é de opção inicial. Reduzem a dor, rigidez matinal e o número de articulações com artrite, porém não modificam o curso da doença ${ }^{1}$. Os principais eventos adversos afetam o tubo digestivo, como dor abdominal, náusea, diarréia e mais raramente, úlcera péptica ${ }^{37}$. Os AINH liberados pelo Food and Drug Administration (FDA) são ácido acetil-salicílico, naproxeno, ibuprofeno e tolmetina.

- Corticosteróides:

Indicação bastante limitada e inclui a presença de manifestações sistêmicas graves como pericardite, pleurite, iridociclite, síndrome de ativação macrofágica ${ }^{38}$ e doença articular grave não responsiva às terapêuticas habituais. O uso deve ser cauteloso, pois apresenta importantes eventos adversos, destacando supressão do crescimento, obesidade, catarata, glaucoma e osteoporose ${ }^{39}$. Os corticosteróides empregados via intra-articular têm mostrado bons resultados no tratamento de artrite persistente, de uma ou duas articulações, que não responderam aos AINH 37. 
- Drogas de base ou drogas anti-reumáticas modificadoras do curso da doença ou drogas anti-reumáticas de ação lenta e agentes biológicos:

Estas drogas modificam a progressão da doença. Suas indicações incluem doença grave, ativa, não responsiva ao uso de AINH, com lesões articulares radiológicas (cistos, erosões e diminuição do espaço articular) e corticodependência ${ }^{40}$. Entre estas drogas podem ser utilizadas cloroquina, metrotexato, sulfasalazina, azatioprina, ciclosporina, ciclofosfamida, isoladamente ou em associação. Os estudos controlados com drogas de base evidenciam que o metrotexato é a droga de escolha dos pacientes que não respondem aos antiinflamatórios não-hormonais ${ }^{1}$.

A terapia combinada é utilizada em pacientes com AlJ. Ela baseia-se na suposição de que associação de drogas alterará a farmacodinâmica com subseqüente efeito aditivo ou sinérgico; além do que doses menores poderiam melhorar o índice de eficácia ${ }^{37}$.

Atualmente, para casos refratários são utilizados os agentes biológicos, particularmente, nas formas sistêmicas e poliarticular: gamaglobulina endovenosa, etanercepte e infliximabe.

3.1.10. Prognóstico

O prognóstico da AlJ parece depender, de maneira importante, do tipo de início da doença e de seu comportamento, após períodos de observação variáveis. Nas fases iniciais, o curso da doença é praticamente imprevisível, 
e se torna mais repetitivo após o estabelecimento de um padrão de comportamento ${ }^{1}$.

A forma oligoarticular apresenta o melhor prognóstico dentre as diferentes formas de AIJ. Geralmente, a maioria dos pacientes terá curso oligoarticular e persistente por dois a cinco anos. Cerca de $20 \%$ dos pacientes desenvolverão um curso poliarticular ${ }^{23}$. Num período de aproximadamente cinco anos após o início da doença, cerca de $25 \%$ dos pacientes apresentam curso de doença contínuo e 60\% apresentam remissão da doença ${ }^{16}$.

$\mathrm{Na}$ forma poliarticular após 5 anos do início da doença, aproximadamente $25 \%$ dos pacientes encontram-se em remissão ${ }^{16}$.

Por sua vez, na forma sistêmica, apenas $10 \%$ dos pacientes apresentam remissão após cinco anos do início sendo que 40\% apresentam destruições articulares graves que não regridem no decorrer dos $\operatorname{anos}^{16}$, sendo considerada por muitos autores como a forma de pior evolução.

As formas poliarticular e sistêmica, além de apresentarem pior prognóstico, também são as formas onde o comprometimento da ATM é mais freqüente e mais grave.

\subsection{SISTEMA ESTOMATOGNÁTICO}

\subsubsection{Conceito}


O sistema estomatognático compreende bases ósseas (maxila e mandíbula), articulação temporomandibular, periodonto, osso alveolar, dentes, sistema neuromuscular e ligamentos. Para que este sistema seja funcionalmente perfeito é necessário que seus componentes estejam em equilíbrio.

\subsubsection{Articulação Temporomandibular (ATM)}

É uma articulação do tipo sinovial, com movimentos complexos de abertura, fechamento, lateralidade, retrusão e protrusão, em que há rotação e translação do côndilo mandibular. É formada pela cavidade articular do osso temporal e pelo côndilo mandibular, que são revestidas por tecido fibroso. As superfícies articulares são separadas pelo disco articular, que divide a articulação em dois compartimentos (superior e inferior), e estão envolvidas por uma cápsula de tecido fibroso, onde internamente encontrase a membrana sinovial, que secreta o líquido sinovial responsável por lubrificar as superfícies articulares, aumentar eficiência funcional e reduzir riscos de erosão óssea. A inervação é essencialmente trigeminal, estando presentes terminações nervosas livres (dor), de Ruffini (propriocepção), de Golgi (mecanocepção) e de Pacini (mecanocepção dinâmica e acelerador de movimento) $41,42,43,44$.

Histologicamente, as superfícies articulares do côndilo e cavidade articular são compostas por quatro camadas distintas: camada articular: é a camada mais externa, avascular, formada por tecido conjuntivo denso 
fibroso, onde as fibras colágenas estão orientadas paralelas à superfície articular; camada proliferativa: composta por células indiferenciadas com alta atividade mitótica, que podem se diferenciar em fibroblastos ou condroblastos. No adulto é uma camada delgada, incompleta e até mesmo ausente; camada de fibrocartilagem: inicia-se após o término da ossificação endocondral, é composta por fibras colágenas dispostas num padrão cruzado. Em indivíduos jovens, a articulação apresenta, subjacente à camada proliferativa, uma região onde está ocorrendo ossificação endocondral para o crescimento mandibular; e finalmente o osso ${ }^{45}$.

Forças biomecânicas dentro dos limites biológicos resultam em adaptação e remodelamento dos componentes articulares e ajudam na manutenção de uma função aceitável. No entanto, sob condições adversas o remodelamento da ATM pode se tornar extensivo e na evolução com inflamação crônica pode levar a alterações na forma dos componentes articulares, como osteoporose, diminuição do espaço articular, cistos, erosões marginais e anquilose óssea, podendo interferir com a função articular, e muitas vezes levar a uma disfunção ${ }^{44,46}$.

Disfunção temporomandibular (DTM) são anormalidades da ATM, que provocam dores recorrentes, habitualmente crônicas, não progressivas e associadas a impacto leve ou moderado na vida dos doentes. Pode ser muscular, articular ou mista, com etiologia ainda não totalmente compreendida, porém com fatores de risco envolvidos em sua gênese, como: o sexo, com maior prevalência de DTM nas mulheres; a idade; anormalidades da oclusão dentária ${ }^{47}$, onde cinco condições oclusais 
parecem aumentar o risco para a ocorrência de dor e disfunção articular, como mordida aberta anterior, sobrepasse horizontal superior a $6 \mathrm{~mm}$, discrepância entre oclusão central $(\mathrm{OC})$ e relação central $(\mathrm{RC})$ superior a 4 $\mathrm{mm}$, mordida cruzada posterior unilateral e perda de cinco ou mais dentes posteriores $^{48}$, parafunção mandibular, fatores emocionais e doenças sistêmicas crônicas ${ }^{47}$. Estes fatores são considerados suficientes, mas nem sempre necessários para 0 desenvolvimento de disfunção temporomandibular ${ }^{49,50}$. Fatores locais como odontalgias, periodontopatias, infecções de vias aéreas superiores muitas vezes intensificam a sintomatologia destas disfunções, ou podem atuar como fatores contribuintes, ou ainda confundir o diagnóstico clínico ${ }^{51}$.

Sinais e sintomas comuns relacionados à disfunção articular ${ }^{51}$, são:

a) ruídos articulares;

b) limitação de abertura bucal;

c) dor a função;

d) alteração dos movimentos mandibulares

e) alterações radiográficas.

A prevalência dos sintomas é baixa na infância, aumenta na fase adulta jovem e tende a declinar na meia idade ${ }^{52}$. Em crianças e adolescentes, a prevalência de DTM varia de 6 a $68 \%$, e esta variação é explicada principalmente pelas diferenças nos critérios diagnósticos utilizados ${ }^{53}$.

Num estudo realizado por List et al, $1999{ }^{53}$, foi observado que os mais prevalentes locais de dor na região cefálica relatados pelas crianças examinadas foram dores de cabeça (21\%), região temporal (12\%), dor à 
abertura bucal e ou à mastigação (4\%) e dor em face, mandíbula ou ATM (3\%). A prevalência de sintomas de DTM relatados pelas crianças foi de $11 \%$ para ruídos, $3 \%$ sensibilidade e cansaço mandibular e $1 \%$ restrição de abertura de boca. Após exame específico entre as crianças que se queixavam de algum sintoma na região cefálica, $70 \%$ delas tiveram o diagnóstico de DTM muscular, 17\% deslocamento de disco e $20 \%$ artralgia, artrite e artrose. Os autores concluíram que a prevalência de DTM tende a aumentar com a idade, sintomas de DTM foram mais freqüentes nas meninas e amplitude de abertura de boca foi menor nos pacientes com DTM.

Vanderas, $1989{ }^{54}$, avaliando a prevalência de sintomas de DTM em crianças, observou que no grupo de crianças "não calmas" os sintomas foram mais freqüente que no grupo de crianças "calmas". $72 \%$ das crianças do grupo "não calmo" apresentaram sintomas objetivos de DTM e $40 \%$ sintomas subjetivos. Dor a palpação de ATM foi observado em $19 \%$ das crianças do grupo "não calmo" e em 7,2\% no grupo "calmo". $67,6 \%$ das crianças do grupo "não calmo" apresentaram dor a palpação muscular, enquanto no grupo "calmo" $46,8 \%$ apresentaram este sintoma. O autor conclui que as crianças têm mais sinais clínicos de DTM que sintomas subjetivos, provavelmente pelos sinais subclínicos serem manifestados antes dos sintomas subjetivos e que a prevalência de sinais e sintomas de DTM pode estar relacionada ao estado emocional das crianças avaliadas.

A ATM é responsável por parte do crescimento mandibular, pois o mais importante centro de crescimento da mandíbula localiza-se no côndilo. Inflamação crônica nessa articulação na fase de crescimento, além da 
possível presença de sinais e sintomas de disfunção, poderá afetar o crescimento facial, resultando em micrognatia, assimetria facial e má oclusão dental entre outros distúrbios do crescimento ${ }^{55}$.

\subsubsection{Dentes e Oclusão}

Os dentes podem interferir no equilíbrio do sistema estomatognático através de patologias dentárias e de seu posicionamento no arco.

A patologia mais comum que afeta os dentes é a cárie dental, que é um processo mediado por microorganismos, caracterizado pela desmineralização da parte inorgânica e destruição da parte orgânica que tem como fatores essenciais para sua ocorrência a dieta, o dente e os microorganismos e como fatores secundários a higiene oral e a saliva ${ }^{56}$.

Inicialmente o processo de cárie atinge estruturas dentárias mais superficiais como o esmalte e a dentina. Na medida em que o processo evolui, pode atingir a polpa dental, favorecendo a invasão bacteriana, produzindo necrose e podendo evoluir para um abscesso dento-alveolar.

Quanto ao posicionamento, os dentes relacionam-se nos arcos dentários

de uma forma harmônica entre si, caracterizando a oclusão fisiológica. Quando esta relação não é adequada, resulta em má oclusão, podendo levar danos ao sistema.

Angle considerou a relação dos primeiros molares permanentes como a "chave de oclusão", pois estes são os primeiros dentes permanentes a 
erupcionar, e assim constituem-se em um ponto de referência notavelmente estável no que diz respeito a anatomia craniofacial ${ }^{57}$.

Baseado na "chave de oclusão", onde a cúspide mésio vestibular do primeiro molar superior oclui com o sulco vestibular do primeiro molar inferior, Angle classificou as anomalias de oclusão dental em três tipos ${ }^{57}$ :

a) Classe (Cl) I: relação molar em "chave de oclusão", podendo haver apinhamento em dentes anteriores;

b) Classe (Cl) II: o primeiro molar inferior está em uma posição distal em relação ao primeiro molar superior;

c) Classe (Cl) III: o primeiro molar inferior está mesialmente colocado em relação ao primeiro molar superior.

Na dentição decídua, a "chave de oclusão" se estabelece entre os segundos molares decíduos.

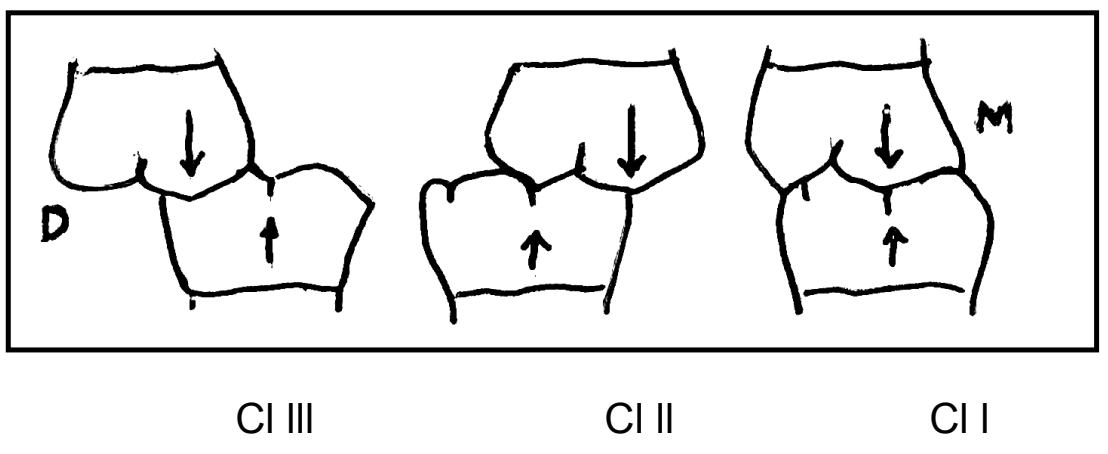

Fig. 1 - Desenho esquemático da relação entre os $1^{\circ}$ molares. À esquerda, molar inferior mesialmente colocado em relação ao superior (Cl III de Angle); ao centro, há distalização do molar inferior ( $\mathrm{Cl}$ II de Angle); e à direita, estas relações são normais (CI I de Angle). D - distal; M - mesial 


\subsubsection{Periodonto}

O dente é suportado pelo osso alveolar através de um sistema ligamentar: o periodonto. Este compreende os seguintes tecidos: a) gengiva; b) ligamento periodontal; c) cemento radicular e d) osso alveolar ${ }^{58}$.

A relação dente-periodonto é uma articulação semi-rígida do tipo gonfose, ricamente vascularizada e inervada, principalmente por mecanoceptores e participa ativamente da sensibilidade táctil do aparelho mastigatório ${ }^{51}$.

O periodonto é acometido, numa maior freqüência, por lesões infecciosas ou traumáticas, mas também pode sofrer alterações decorrentes de síndromes congênitas, distúrbios autoimunes ou ectodérmicos ${ }^{58}$.

Dentre as lesões infecciosas, estão doenças periodontais como a gengivite e a periodontite. A gengivite é caracterizada pelo estado inflamatório dos tecidos gengivais quando expostos à placa bacteriana. $A$ periodontite representa a perda do osso alveolar e o dano extenso às fibras do ligamento periodontal, com migração do epitélio juncional e manifestações disseminadas do processo inflamatório e imunopatológico nos tecidos ${ }^{58}$.

Estas doenças apresentam como fator etiológico o acúmulo de placa bacteriana associado a fatores de risco como componente genético de susceptibilidade a doença periodontal, idade, algumas condições sistêmicas onde há um comprometimento do sistema imune, o fumo e a presença de 
determinadas bactérias na placa bacteriana. A instalação, permanência e progressão da doença periodontal dependerá basicamente desses fatores ${ }^{58}$.

Alguns medicamentos apresentam como manifestação periodontal, aumento gengival. A ação sistêmica da ciclosporina leva a um acúmulo de colágeno e proteínas não colagenosas; isto em nível gengival reflete em acantose e hipertrofia do estroma, resultando em aumento gengival numa freqüência de 10 a $70 \%$, dependendo da dose de ciclosporina utilizada ${ }^{58}$.

\subsection{CRESCIMENTO FACIAL EM PACIENTES COM AIJ}

Distúrbios no crescimento facial em pacientes com AlJ foi primeiramente descrito por Diamant-Berger em 1891, que evidenciou o subdesenvolvimento da mandíbula e a típica "face de pássaro" (aumento do ângulo FM (Frankfurt-mandibular), rotação posterior da mandíbula com sínfise inclinada anterior e concavidade do bordo inferior e retrognatia mandibular com redução da altura facial posterior) ${ }^{59}$, porém esta não pode ser considerada patognomonica destas crianças pois é observada em apenas 10 a $30 \%$ destes pacientes ${ }^{11}$

Os efeitos da AIJ no crescimento facial é provavelmente mutifatorial. A artrite na ATM, com acometimento do côndilo no período de desenvolvimento é o mais importante fator que inibe o crescimento da mandíbula e conseqüente crescimento facial nestes pacientes $3,4,55,60,61,62$, 63,64. Outros fatores foram estudados tentando estabelecer suas relações com as alterações de crescimento. O uso prolongado de corticosteróides, 
acima de três meses, parece influenciar o tamanho mandibular ${ }^{3,55}$, por sua ação prejudicial ao crescimento, e também por reduzir a densidade de estruturas ósseas da ATM, facilitando deformidades ${ }^{60}$, porém esta relação não foi observada em outros estudos ${ }^{5,65,66}$, considerando que a utilização prolongada de corticosteróides reflete apenas maior gravidade da doença e não necessariamente um papel patogênico específico destas drogas na ATM 5. A influência do comprometimento cervical no crescimento facial é outro fator estudado, sendo descrito que afecções cervicais são mais freqüentes em pacientes com alterações de $\operatorname{ATM}^{65}$, sendo que as alterações na postura da cabeça podem causar alterações na posição da mandíbula durante o crescimento, sem interferir com o tamanho mandibular ${ }^{3}$. 0 prejuízo da função mandibular por dor ou por diminuição do tônus muscular também é apontado como possível fator causal nas alterações de crescimento facial em crianças com AlJ ${ }^{55,59,67,68}$, por diminuir a estimulação funcional do crescimento condilar e mandibular ${ }^{64}$.

O crescimento potencial da mandíbula é maior nos primeiros anos de vida, sendo que a inibição deste crescimento é maior quanto mais precoce for o envolvimento da ATM pela doença ${ }^{3,9,59,69,70,}$. Num estudo onde foi avaliada a morfologia radiográfica da ATM normal de recém-nascidos comparativamente a articulações artríticas com micrognatia, observou-se que há uma similaridade de morfologia entre os diferentes grupos, sugerindo um envolvimento precoce das ATMs, nos pacientes que desenvolvem micrognatia $^{71}$. 
Assim como a idade de início da doença, fatores como maior tempo de duração, curso e tipo de início e de evolução, parecem aumentar o risco de envolvimento da ATM e tornar pior o prognóstico para esta articulação ${ }^{5,55}$, 70. Ao se comparar alterações no crescimento facial com tipo de início da doença, observa-se que crianças com início sistêmico apresentam alterações faciais freqüentes ${ }^{7}$, e no início poliarticular as alterações são mais freqüentes e mais graves que no início pauciarticular ${ }^{72}$, sendo considerados os tipos de início sistêmico e poliarticular fatores de risco para o acometimento da ATM $^{5,9}$. Assim, variações e gravidade da doença e de suas exacerbações podem explicar porque as mandíbulas podem ser afetadas diferentemente ${ }^{72}$.

As principais características faciais presentes em pacientes com AlJ são:

a) micrognatia, observada em 4 a $60,7 \%$ dos pacientes 8,62 principalmente em pacientes com comprometimento bilateral das ATMs; o ramo mandibular está encurtado 4,70,73,74 em aproximadamente $51,4 \%$ dos pacientes ${ }^{61}$ bem como todas as dimensões mandibulares encontram-se reduzidas ${ }^{4,55,59,70,74,75}$;

b) assimetria facial, observada em pacientes com comprometimento unilateral da ATM $54,74,76,77$;

c) retrognatia $4,63,70,78,79$;

d) relação molar $\mathrm{Cl}$ II de Angle, observada em 21 a $69 \%$ dos pacientes 5, 69.

e) mordida aberta anterior 4,67 , observada em $80 \%$ dos pacientes com lesões condilares graves ${ }^{5}$; 
f) perfil convexo ${ }^{69,73}$, observado em $100 \%$ dos pacientes com lesões condilares graves e $30 \%$ dos pacientes sem leões condilares ${ }^{5}$;

g) rotação posterior da mandíbula, 4, 59, 63, 67, 70;

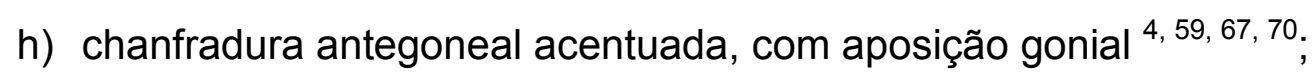

i) apinhamento anterior inferior, com incisivos proclinados ${ }^{55}$;

j) comprimento facial posterior menor ${ }^{59,70}$.

As principais alterações ocorrem na mandíbula, sendo que na maxila pode ser observado desenvolvimento normal 4,64 ou redução no comprimento vertical maxilar, principalmente nas crianças que apresentam comprometimento mandibular ${ }^{59,55}$.

Tavakoli-jou, et al ${ }^{64}$, em 1999 num trabalho experimental, avaliaram o crescimento facial em coelhos com artrite induzida na ATM, comparado a controles normais e observaram alterações nas estruturas mandibulofaciais. Em estágios precoces da artrite, os achados entre os grupos foram similares, no entanto com a "cronificação" observaram que as dimensões maxilares sagitais foram semelhantes, bem como o desenvolvimento dentário posterior, porém as dimensões mandibulares foram reduzidas nos animais artríticos. Todas as alterações parecem convergir na região condilar, sendo o mais importante fator das alterações observadas a destruição morfológica da cabeça do côndilo, que pode não apenas causar diminuição do crescimento da cartilagem como também resultar em deslocamento físico da mandíbula, com posicionamento posterior e rotação do corpo mandibular.

Quando o crescimento condilar está comprometido há uma aposição óssea no bordo posterior do ramo e em região de sínfise anterior, no entanto 
não é suficiente para compensar a atividade reduzida na cartilagem condilar $^{4,59}$.

As alterações do crescimento facial não podem ser consideradas indicativo exclusivo de comprometimento condilar. Pearson et al, $1996{ }^{66}$ observaram que $42 \%$ das crianças com alterações do crescimento facial, apresentaram anormalidades condilares graves e que $21,8 \%$ das crianças com AIJ e crescimento facial normal, apresentaram vários níveis de destruição condilar, concluindo que estas crianças podem apresentar grave envolvimento articular e manter crescimento facial normal.

O tratamento para correção das alterações do crescimento facial em crianças com AlJ, não está bem estabelecido, sendo descritos na literatura, na maioria das vezes, apenas como relatos de caso. Fatores como défict funcional, extensão de deformidade visual, atividade da doença, crescimento físico, desenvolvimento dental e aspectos psicológicos determinam as opções de tratamento ${ }^{80}$.

Uma opção é a realização de cirurgias (ortognática, mentoplastia, sinovectomia e condilectomia), com o objetivo de restaurar alterações faciais, melhorar a estética e possibilitar o crescimento mandibular, e foram demonstrados bons resultados nos casos relatados ${ }^{4,81}$. Estas cirurgias podem ser realizadas ainda na fase de crescimento ${ }^{82,83,84}$.

Aparelhos ortopédicos funcionais são recomendados para reduzir a pressão no côndilo afetado, agindo como "protetor articular" 8, 67, 68, 85 e, embora haja controvérsias do quanto a morfologia e crescimento facial podem ser influenciados por ortopedia funcional, alguns relatos de caso têm 
mostrado que mudanças no crescimento mandibular pode ser induzida por alterações na posição mandibular ${ }^{68,86}$, pela possibilidade de se conseguir crescimento mandibular sem a presença de cartilagem condilar ${ }^{68}$. Outra explicação para resultados favoráveis no tratamento destas crianças pode ser o crescimento alcançado nos côndilos afetados precocemente, antes da ocorrência de atividade hiperplástica intensa, por artrites temporárias causando danos reversíveis, permitindo a expressão de um padrão de crescimento normal para estes pacientes ${ }^{87}$. Em um relato de caso clínico foi mostrado, com a utilização de aparelho funcional por um ano em uma paciente com AlJ e alterações do crescimento facial, melhorou o perfil, correção do "overjet" e aposição óssea no teto da fossa glenóide e nas regiões superior e posterior dos côndilos ${ }^{86}$. Já num trabalho realizado para avaliar os efeitos do aparelho funcional em 30 crianças com AlJ, concluíram que a sua utilização melhora significativamente as relações oclusais, embora não se comprovasse sua ação na melhora do perfil ${ }^{70}$. Os resultados dos tratamentos ortodônticos compensatórios não podem ser considerados estáveis nestas crianças em razão dos episódios cíclicos da doença sistêmica ${ }^{88}$. Alguns autores preconizam o uso de aparelhos ortopédicos maxilares ${ }^{8}$ para tentar minimizar os efeitos da doença sobre o crescimento mandibular. Neste caso a ativação do aparelho não deveria ser realizada nos períodos de atividade da $\mathrm{AlJ}^{68}$, pois nesta fase sua ação poderia ser prejudicial, contribuindo para maior perda óssea ${ }^{89}$. 


\subsection{DISFUNÇÃO TEMPOROMANDIBULAR EM PACIENTES COM AIJ}

O comprometimento da ATM pela AlJ é observado não apenas pelas alterações do crescimento facial, mas também pela presença de sinais e sintomas de disfunção desta articulação, como dor (espontânea e ao movimento), limitação de função, diminuição da mobilidade mandibular, presença de ruídos articulares e alterações radiográficas ${ }^{69}$. Normalmente o acometimento da ATM é observado em conjunto a outros sinais e sintomas da AIJ, no entanto Martini et al, $2001^{90}$ relatam um caso clínico de artrite da ATM como a única manifestação desta doença.

Aproximadamente 37 a $65 \%{ }^{8,65}$ dos pacientes com AlJ apresentam sinais e sintomas de disfunção e estes parecem estar relacionados à idade dos pacientes, com menor freqüência de sinais e sintomas em crianças menores de sete anos ${ }^{91}$, e a fatores da doença, e por esta razão nem sempre estão presentes ${ }^{92}$. A forma de início poliarticular apresenta mais queixas e anormalidades na ATM que a pauciarticular ${ }^{5,72}$. A extensão do envolvimento da ATM é maior na forma sistêmica, média na poliarticular e menor na pauciarticular ${ }^{61}$, com as formas poliarticular e sistêmica apresentando maior freqüência de sinais e sintomas ${ }^{9}$. O início precoce, maior tempo de duração da doença e a gravidade dos doentes, também aumentam a freqüência e a intensidade de anormalidades articulares ${ }^{8,61,65,}$ ${ }^{76,93}$, e atividade da doença mantida por maior tempo, aumenta o prejuízo da capacidade funcional ${ }^{93,76}$. 
Marini et al, $1999^{88}$, compararam crianças reumáticas com crianças saudáveis que apresentavam mordida aberta anterior a fim de esclarecer se mordida aberta anterior, por si só, pode favorecer o aparecimento de sinais e sintomas de DTM e encontraram diferença no desvio mandibular, sensibilidade muscular e dor espontânea no grupo com AIJ e no grupo com mordida aberta houve diferença significante na prevalência de mordida cruzada unilateral.

A dor é um sintoma importante de comprometimento da ATM, e é queixa presente em aproximadamente 30 a $56 \%$ dos pacientes com AlJ ${ }^{8,91}$, sendo que $49 \%$ dos pacientes consideram sua dor de baixa intensidade ${ }^{8}$. A dor pode ser articular, observada em $19 \%$ dos pacientes ${ }^{69,91}$ e explicada pela própria artrite, e muscular, observada em $33 \%$ dos pacientes ${ }^{69}$, e pode decorrer das alterações histológicas e histoquímicas encontradas no músculo de pacientes com AIJ, provavelmente em razão da oclusão instável e das anormalidades do crescimento facial presentes ${ }^{67}$, como também pode ser secundária aos fenômenos de dor ${ }^{8,88,91,94 .}$

Apesar de ser mais prevalente em pacientes com AlJ, quando comparadas a controles saudáveis ${ }^{8,91,94}$, a dor não pode ser considerada um indicador confiável de envolvimento da articulação temporomandibular ${ }^{62,}$ 95. Tanchyk, $1994^{92}$, relata o caso de uma paciente com AIJ que apresentava alterações do crescimento facial e envolvimento articular comprovado radiograficamente e que, no entanto não apresentava dor. Svenson et al, $2001^{95}$, acreditam que o uso de medicações antiinflamatórias pode mascarar este sintoma. O medo de novos tratamentos ao apresentarem novas 
queixas, juntamente com a dificuldade natural de mensurar dor em crianças, uma vez que o entendimento e a habilidade em expressar dor dependem do estágio de desenvolvimento cognitivo que elas apresentam, também são apontados como possíveis explicações para a baixa prevalência desta queixa na região orofacial ${ }^{91}$. Dor reflete uma fase ativa da doença, mais do que degeneração condilar ${ }^{95}$. A queixa de dor no segmento cefálico exige exame minucioso e a realização do diagnóstico diferencial com outras fontes de dor ${ }^{51,96}$.

Harper, $2000^{34}$, com o objetivo de determinar a relação entre DTM, dor e desempenho mastigatório em crianças com AlJ, observou prejuízo mastigatório nas crianças com AIJ que apresentavam DTM, e atribui estes resultados possivelmente a mecanismos de evitação de dor, com prejuízo da função.

A redução da amplitude dos movimentos mandibulares também é observada em pacientes com $\mathrm{AlJ}^{7}$, 9, 69, 94, 97, sendo a restrição de abertura de boca considerada o mais real dado clínico de prejuízo mandibular ${ }^{65}$. Diminuição da mobilidade mandibular é observada em 30 a $75 \%$ dos pacientes 65, 93, 98 e correlaciona-se ao reduzido movimento do côndilo, provavelmente pela artrite na ATM, pelo envolvimento muscular e adesão dos componentes articulares em estágios avançados ${ }^{94,98}$, podendo resultar em anquilose desta articulação ${ }^{99}$.

Ruído é outro sinal de DTM que pode ser observado nestas crianças. Está presente em 18 a $57 \%{ }^{8,61,69}$ dos pacientes, sendo o ruído mais 
freqüente a crepitação, a qual relaciona-se a alterações degenerativas das ATMs ${ }^{91,94}$.

Alterações radiográficas na ATM indicam comprometimento desta articulação e podem ser observadas em aproximadamente 29 a $80 \%$ 7, 8, 13, 69, 70, 93 dos pacientes com AlJ. A diferença na prevalência de alterações radiográficas pode ser explicada por diferenças de gravidade da amostra e pelo tipo e precisão do exame utilizado em cada estudo ${ }^{2,6,7,91}$.

A radiografia panorâmica de face é um exame muito utilizado na avaliação do sistema mastigatório por dar uma visão geral de ossos maxilares, dentes e ATM ${ }^{100}$. É exame de simples execução, baixa radiação e baixo custo, porém não é um exame de muita precisão ${ }^{2}$, e pode apresentar erros quando se deseja realizar medidas ${ }^{77}$. Em AlJ, é utilizado na avaliação das alterações da ATM $^{13,65,66,71,77,94}$, na avaliação de dentes e de dimensões condilares e mandibulares ${ }^{70}$. É o melhor instrumento para avaliação inicial e para o seguimento das complicações da AIJ na ATM ${ }^{2}$.

Tomografia computadorizada de alta resolução também é utilizada em pacientes com AlJ, tem a vantagem de mostrar finas alterações ósseas, indistinguíveis em radiografias convencionais, podendo revelar mudanças degenerativas precoces da ATM $^{6,101}$.

A utilização da Ressonância Nuclear Magnética tridimensional para visualização da ATM, possibilita visualização dos tecidos moles da ATM sendo considerado o exame mais preciso para o diagnóstico de envolvimento desta articulação ${ }^{86,98}$. 
As alterações condilares frequentemente observadas nos exames de imagem são erosões ósseas, vista em aproximadamente $23 \%$ dos pacientes 6, 73, 101, aplainamento da superfície condilar, observada em $66 \%$ dos pacientes $^{6,7,94}$, diminuição do espaço articular ${ }^{6,73}$, esclerose da superfície $\operatorname{articular}^{79}$ e presença de osteófitos ${ }^{98}$. O disco pode se encontrar deslocado posterior, provavelmente em decorrência do processo destrutivo que pode levar a segmentação do disco articular ${ }^{98}$. Pearson et al, $1996{ }^{66}$, avaliando radiograficamente 71 crianças por 23 anos observaram que o envolvimento articular é assimétrico em estágios precoces, tornando-se simétrico à medida que a doença avança.

Assim como o comprometimento do crescimento facial, a presença e extensão de alterações radiográficas parecem estar associadas a fatores da doença como início precoce ${ }^{2,65}$, maior tempo de duração e maior gravidade da doença ${ }^{2,6,13,65,76}$, ao tipo de início, com maior extensão de alterações no início poliarticular quando comparado ao pauciarticular ${ }^{65}$, e no sistêmico quando comparado ao poliarticular ${ }^{6,61,72}$. Pedersen et al, $2001^{13}$, observaram maior freqüência de alterações condilares nos pacientes com início poliarticular, comparativamente ao início pauciarticular e sistêmico, no entanto a gravidade das alterações foi maior no início poliarticular quando comparada ao pauciarticular, sem diferenças quando comparada ao início sistêmico. Pacientes com FAN positivo apresentam alta prevalência de alterações radiográficas, e nos pacientes que apresentam HLA - B27 positivo a prevalência é baixa, no entanto em ambos os grupos as alterações são de 
pouca gravidade. Os pacientes com lesões condilares graves, apresentam mais queixas na região orofacial e mais alterações faciais ${ }^{5,55}$.

$\mathrm{Na}$ avaliação radiográfica, os sinais de envolvimento da ATM excedem os sintomas clínicos, podendo os pacientes ser assintomáticos mesmo com a presença de graves alterações na $\operatorname{ATM}^{8,9}$, por isto a avaliação periódica com radiografia panorâmica é recomendada para todas as crianças com AIJ 2, 8 . Alterações degenerativas não necessariamente são acompanhadas por dor ${ }^{95}$, e da mesma forma é possível a ocorrência de sintomas, mesmo sem alterações morfológicas na ATM $^{72}$.

Twilt et al, $2004^{2}$, avaliando quais sintomas clínicos são válidos como indicativos de artrite na ATM observaram que dor à excursão mandibular, ausência de translação, assimetria durante máxima abertura de boca e protrusão, bem como crepitação, são bons indicativos da artrite, com boa especificidade, mas com baixa sensibilidade.

$\mathrm{Na}$ avaliação macroscópica e histológica de ATMs de pacientes com alterações radiográficas e do crescimento facial, observou-se tecido de granulação em todo compartimento inferior e no disco articular, compatível com pannus, entre a superfície articular dos côndilos e o disco, enquanto os compartimentos superiores foram livres de tecido de granulação e adesão, sugerindo um envolvimento polarizado, de razão desconhecida. Vários níveis de remodelação óssea podem ser observados, com células inflamatórias crônicas presentes em números variados ${ }^{95,102}$.

Prejuízo funcional do sistema mastigatório também é observado em pacientes com AlJ. A força de contração dos músculos temporal e, 
principalmente masseter, está reduzida nestes pacientes, com conseqüente redução da força de mordida e do tempo de máxima contração ${ }^{67,93,94}$. Num estudo realizado por Kjellberg et al, $1995^{70}$, que teve como objetivo avaliar as características mastigatórias de pacientes com AlJ, comparativamente a indivíduos saudáveis que apresentavam relação molar $\mathrm{Cl}$ I e $\mathrm{Cl}$ II de Angle, observaram que os pacientes com AlJ apresentavam redução dos movimentos mandibulares bordejantes e da capacidade translatória do côndilo mandibular. Nas crianças onde AIJ estava associada à má oclusão Cl II, foi observado maior tempo na fase oclusal do ciclo mastigatório, menor amplitude e menor velocidade de movimentos, concluindo que AlJ e alteração oclusal isolados, não exercem muita influência nos movimentos mastigatórios, no entanto, a interação destes dois fatores resulta em um padrão mastigatório alterado.

\subsection{CONSIDERAÇÕES DENTAIS E PERIODONTAIS EM PACIENTES COM AlJ}

$\mathrm{Na}$ AlJ, a saúde oral pode ser comprometida em razão da própria doença ou de fatores secundários a ela, predispondo estas crianças a doenças dentárias e periodontais, provavelmente por razões multifatoriais, apesar de existirem poucos trabalhos na literatura que abordem estes aspectos.

Crianças com AlJ apresentam maior prevalência de cáries quando

comparadas a controles saudáveis, utilizando-se o Índice CPO-D 12, 18, 103, 
104. Grosfeld, $1973^{69}$, descreveu que dos pacientes com AlJ avaliados, $12 \%$ apresentaram cáries extensas e $28 \%$ perda prematura de dentes decíduos, considerando estes resultados similares aos observados na população geral. Welbury et al, $2003^{12}$ avaliaram a prevalência de dentes cariados, perdidos e obturados em crianças com AlJ comparando-as a controles saudáveis e observaram que a freqüência de dentes cariados e perdidos é maior em crianças com AlJ, com tendência a apresentarem menor número de dentes obturados, sugerindo que estes pacientes além de serem mais propensos a cáries dentárias, freqüentam menos os consultórios dentários do que os controles.

Alguns fatores podem estar associados à maior predisposição destas crianças a doenças bucais, como:

- Dificuldade em realizar higiene oral, pela limitação de abertura de boca devido ao envolvimento da ATM, e também pelo comprometimento de articulações de membros superiores, o que dificulta a empunhadura e correto manuseio da escova e fio dental ${ }^{10}$, $11,18,103,104,105$

- Utilização de medicações açucaradas para controle da doença ${ }^{11,104}$.

- Maior ingestão de açúcar, por estas crianças serem frequentemente consoladas com doces ${ }^{60}$;

- Menor freqüência de consultas odontológicas quando comparadas a crianças saudáveis, talvez pelo estado de saúde geral, e menor prioridade ao tratamento dentário ${ }^{12,60}$; 
- A dificuldade de realizar higiene oral pelas crianças com AlJ, aliado ao desconhecimento dos dentistas, seja da doença ou das interações medicamentosas, "atrasam" os tratamentos dentários necessários e piora a saúde oral dessas crianças ${ }^{11,12}$;

- Substituição de alimentos duros por alimentos mais moles que facilitam a mastigação, mas que ficam mais aderidos aos dentes ${ }^{12}$, e

- Alterações bioquímicas da saliva, com concentração de sódio maior que os controles, e cálcio, fosfato, potássio, amilase e $\lg \mathrm{A}$ em concentrações menores que os controles ${ }^{103}$.

O acometimento do periodonto ocorre por dificuldades de realização de higiene oral, resultando em maior inflamação gengival ${ }^{12}$ e por efeitos secundários de medicamentos, como o corticosteróide que predispõe a infecções ou a ciclosporina, que induz hipertrofia gengival ${ }^{10,11}$. Há uma tentativa de alguns autores em estabelecer relação entre doença reumática e doença periodontal, uma vez que o periodonto é uma articulação com igual susceptibilidade à inflamação reumática ${ }^{60}$. A AIJ pode ser considerada um possível cofator de doença periodontal ${ }^{10}$.

Infecções como cáries e doença periodontal são potencialmente exacerbadoras e mantenedoras da atividade da doença ${ }^{12,104}$ e devem ser eliminadas e controladas.

O tratamento odontológico elimina as doenças bucais e possibilita que a saúde oral conseguida, seja mantida por métodos preventivos. O cirurgião dentista deve conhecer e considerar as diversas alterações clínicas nos pacientes com AlJ, estabelecendo diagnóstico e plano de tratamento 
específico ${ }^{10}$. A anemia, habitualmente presente nas crianças com forma sistêmica, é fator comum de importância no tratamento dental, requerendo atenção especial em procedimentos cirúrgicos ou sob sedação ${ }^{11}$. Os efeitos de múltiplas medicações usadas no tratamento da AlJ devem ser considerados, como os antiinflamatórios não hormonais que estão associados a úlceras bucais e ao aumento do tempo de sangramento. As drogas imunossupressoras podem causar estomatite ulcerativa e discrasias sanguíneas. O uso prolongado de corticosteróide pode alterar a cicatrização, aumentar susceptibilidade à infecção, suprimir o crescimento e causar osteoporose ${ }^{10}$. E as úlceras bucais secundárias ao Metrotexato podem intensificar os problemas ${ }^{11}$.

A prevenção é fundamental no controle das doenças bucais minimizando intervenções. Deve ser realizada orientação de higiene oral às crianças e aos seus pais, com adaptações específicas quando necessário inclusive com o uso de escovas elétricas ${ }^{10,104,105}$, controle da dieta ${ }^{104}$, aplicação de flúor e de selantes ${ }^{12,104}$.

Oksa et al, $2000{ }^{106}$ com o objetivo de comparar maturidade dental de crianças com AIJ e controles saudáveis, avaliaram o desenvolvimento dental através de radiografias panorâmicas e observaram que a maturidade dental foi significativamente avançada em pacientes com AlJ e sugerem que este resultado seja decorrente principalmente do efeito do tratamento com corticosteróides, sendo que a influência direta da doença necessita ser melhor elucidada. 


\section{MÉTODOS}

\subsection{Casuística}

\section{Pacientes}

Trinta e cinco pacientes de ambos os sexos, acompanhados na Unidade de Reumatologia Pediátrica do Instituto da Criança do Hospital das Clínicas da Faculdade de Medicina da Universidade de São Paulo, com diagnóstico de AIJ, conforme critérios propostos pela ILAR (International League of Associations of Rheumatology), com evolução poliarticular formaram o grupo de estudo.

Grupo controle composto de 35 crianças saudáveis em tratamento odontológico de rotina na Divisão de Odontologia do Instituto Central do Hospital das Clínicas da Faculdade de Medicina da Universidade de São Paulo foi avaliado nas mesmas condições.

\section{Critérios de Inclusão}

- Pacientes com AIJ na forma evolutiva poliarticular;

- Idade igual ou superior a quatro anos.

Critérios de Exclusão

- Comorbidades locais ou outras doenças sistêmicas com repercussões dentárias ou articulares. 
Ética

O estudo foi submetido e aprovado pela Comissão de Ética em Pesquisa do Hospital das Clínicas da Faculdade de Medicina da Universidade de São Paulo (Anexo 1).

\subsection{Métodos}

Todos os pacientes foram submetidos à entrevista e avaliação clínica para coleta de dados sócio-demográficos e clínicos.

\section{Variáveis sócio-demográficas}

Os dados sócio-demográficos coletados foram o gênero e a idade.

\section{Variáveis Clínicas}

Foram coletados os seguintes dados clínicos:

A) Avaliação clínica médica (Anexo 2): idade de início da AlJ, duração da doença, tipo de início e evolução, curso da doença, medicações utilizadas, classificação funcional de Steinbrocker ${ }^{107}$ (classe de I a IV conforme a capacidade de realizar atividades de vida diária), articulações ativas e comprometidas (edema e/ou limitação de movimento) no corpo e especificamente de membros superiores e pacientes com comprometimento da ATM constatado pelo médico, sem exame odontológico específico. 
B) Avaliação de dor orofacial: através de ficha clínica da Equipe de Dor Orofacial/ATM do Hospital das Clínicas da Faculdade de Medicina da Universidade de São Paulo ${ }^{108}$ (Anexo 3), caracterizando eventuais dores presentes no seguimento cefálico como: queixa e duração, localização da dor, fator inicial, tratamentos realizados, tipo de dor, freqüência, intensidade, fatores de melhora e de piora, queixa de otalgia e cefaléia freqüentes.

C) Avaliação periodontal pelos Índices de placa ${ }^{109}$ e de sangramento gengival ${ }^{110}$ (Anexo 4). O Índice de placa foi utilizado para avaliar a condição de higiene oral, calculado pelo número de superfícies dentárias coradas por pastilhas evidenciadoras de placa, multiplicado por 100 e dividido pelo número total de superfícies. Inflamação gengival foi avaliada pelo Índice de sangramento gengival, determinado pelo número de superfícies sangrantes após sondagem com sonda periodontal, multiplicado por 100 e dividido pelo número total de superfícies.

D) Avaliação dentária pelo Índice CPO-D ${ }^{111}$ (Anexo 5): que considera o número de dentes cariados, perdidos e obturados.

E) Avaliação da condição da articulação temporomandibular pelo Índice de Helkimo ${ }^{112}$ em questionário traduzido para a língua portuguesa (Anexo 6). Foi utilizado o Índice de disfunção mandibular clínica (IDC) e o Índice de mobilidade mandibular (IMM). O Índice de disfunção mandibular avalia cinco sinais clínicos de disfunção (mobilidade mandibular, comprometimento da função mandibular, dor a palpação dos músculos mastigatórios, dor a palpação da ATM e nos movimentos mandibulares), com scores de 0 a 5 conforme a gravidade, sendo o resultado final a 
somatória dos scores. Um IDC de 0 denota ausência de disfunção; de 1-4, leve; 5-9, moderada e 10-25, disfunção grave. O Índice de mobilidade mandibular avalia a amplitude dos movimentos mandibulares (abertura interincisal máxima, lateralidade direita e esquerda e protrusão), com score de 0 a 5, dependendo da gravidade, sendo o resultado final a somatória dos scores. Um IMM de 0 denota mobilidade mandibular normal; 1-4, mobilidade levemente comprometida e de 5-20, mobilidade gravemente comprometida . Foi observado também presença de ruídos articulares.

F) Avaliação do perfil facial e relação molar: o perfil facial foi determinado pela análise facial diferindo três padrões: perfil côncavo, convexo e reto e a relação molar determinada de acordo com a Classificação de Angle, considerando a posição do primeiro molar superior em relação ao primeiro molar inferior.

G) Avaliação Radiográfica (Anexo 7): por radiografia ortopantomográfica (panorâmica) da face para avaliar o esqueleto facial, incluindo os dentes, periodonto, ossos maxilares e componentes visíveis da ATM. As alterações condilares foram classificadas em grau (0): ausência de anormalidades radiográficas, grau (1): defeitos na borda condilar e erosões menores, grau (2): aplainamento do côndilo e grau (3) destruição total do côndilo $^{13}$. Esta avaliação foi feita por 4 examinadores independentes, sendo que nenhum deles sabia a que grupo pertencia o paciente. $O$ examinador 1 é ortodontista, o examinador 2 são dois especialistas em DTM, o examinador 3 é ortodontista e radiologista, e o examinador 4 é radiologista. 


\section{Análise estatística}

Para a análise estatística dos resultados, foram realizados testes paramétricos e não paramétricos. Foram aplicados: teste t de Student para avaliar idade e a amplitude dos movimentos; o teste Qui-quadrado para avaliar gênero, prevalência de queixas e de dor a palpação, índice de disfunção clínica, índice de mobilidade mandibular, e ruídos; teste exato de Fischer para avaliar relação molar, perfil, tipos de queixas, prevalência de alteração condilar e grau de alteração condilar; o índice kappa foi utilizado para avaliar a concordância entre os examinadores; o teste Mann Whitney, para avaliar Índice CPO-D, dentes cariados, dentes perdidos e dentes obturados, Índice de placa e de sangramento gengival, bem como avaliar a relação entre CPO-D, Índice de placa e de sangramento gengival e o número de articulações de membros superiores envolvidas, e para relacionar o tipo de perfil, com a idade de início e o tempo de doença; e o teste Kruskal-Wallis para relacionar Índice de disfunção clínica e de mobilidade mandibular com idade de início da doença e tempo de doença. Em todos os testes estatísticos, o nível de significância foi de $5 \%(p<0,05)$. 


\section{RESULTADOS}

Os dois grupos foram compostos por 35 pacientes cada, sem diferenças de faixa etária ou da distribuição por gênero. Os dados estão apresentados na Tabela 1.

Tabela 1. Distribuição dos grupos quanto ao gênero e à idade.

\begin{tabular}{cccc}
\hline Dados & $\begin{array}{c}\text { AlJ } \\
(n=35)\end{array}$ & $\begin{array}{c}\text { Controle } \\
(n=35)\end{array}$ & $p$ \\
\hline
\end{tabular}

Gênero

$\begin{array}{llll}\text { Feminino } & 25(71,4 \%) & 22(62,9 \%) & 0,445^{*} \\ \text { Masculino } & 10(28,5 \%) & 13(37,1 \%) & \end{array}$

Idade

$\begin{array}{lccc}\text { Mínima } & 4,7 & 5,4 & \\ \text { Máxima } & 20 & 15,4 & \\ \text { Media } & 11,4 \pm 3,47 & 10,4 \pm 2,56 & 0,185^{\star *}\end{array}$

\footnotetext{
${ }^{*}$ Teste Qui-quadrado

**Teste $t$ de Student
}

Na Tabela 2 são apresentados os dados referentes às características clínicas e ao comprometimento das articulações do corpo dos pacientes com AlJ. 
Tabela 2. Comprometimento das articulações do corpo e características clínicas do grupo com AIJ

\begin{tabular}{ll}
\hline Características clínicas & \multicolumn{1}{c}{$\begin{array}{c}\text { AlJ } \\
(\mathrm{n}=35)\end{array}$} \\
\hline Idade de início da doença & $4,7 \pm 3,04$ (1 a 13 anos) \\
Duração da doença & $7 \pm 3,74 \quad(1$ a 16 anos $)$ \\
Tipo de início & Sistêmico: 22 \\
& Poliarticular fator reumatoide \\
& negative: 7
\end{tabular}

Classe Funcional de Steinbrocker

I: 19

II: 9

III: 4

IV: 3

Articulações ativas (pacientes / média de articulação por paciente)

Articulações comprometidas (pacientes / média de articulações por paciente)

Pacientes com articulações de membros superiores comprometidas (até 2 articulações / 3 a 8 $35(17 / 18)$ articulações) 
Medicações em uso pelos pacientes com AlJ

No período de avaliação seis (17\%) não necessitavam de medicação. Vinte e três $(65,7 \%)$ usavam antiinflamatório não hormonal (AINH), 19 $(54,2 \%)$ usavam drogas de base e $11(31,4 \%)$ usavam corticosteróides. Dezessete $(48,5 \%)$ pacientes usavam associação entre as medicações. Os dados podem ser observados na Tabela 3.

Tabela 3: Medicações em uso pelos pacientes com AIJ

\begin{tabular}{lc}
\hline \multicolumn{1}{c}{ Medicações em uso } & AlJ \\
& $(\mathrm{n}=35)$ \\
$\mathrm{N}(\%)$ \\
AINH & $23(65,7)$ \\
Drogas de Base & $19(54,2)$ \\
Corticosteróide & $11(31,4)$ \\
Sem medicação & $6(17)$ \\
\hline
\end{tabular}

Queixas orofaciais

No grupo com AIJ, dez pacientes $(28,5 \%)$ responderam que tinham alguma queixa na boca ou na face: odontalgia em três, dor à mastigação ou durante a abertura de boca em seis, e dificuldade em abrir a boca em um. No grupo controle, seis pacientes $(17,1 \%)$ tiveram queixas: odontalgia em quatro $(11,4 \%)$. Os dados estão na Tabela 4. 
Tabela 4: Distribuição dos grupos quanto à presença de queixas na região orofacial

\begin{tabular}{lccc}
\hline Queixas & AIJ $(n=35)$ & Controle $(n=35)$ & $p$ \\
& $N(\%)$ & $N(\%)$ & $0,255^{*}$ \\
Odontalgia & $3(8,5)$ & $6(17,1)$ & \\
Dor a função & $6(17,1)$ & $1(2,8)$ & $0,241^{* *}$ \\
Limitação AB & $1(2,8)$ & $0(0)$ & \\
Estalo & $0(0)$ & $1(2,8)$ & \\
\hline
\end{tabular}

* teste Qui-quadrado

${ }^{* *}$ teste exato de Fisher.

Relação dentária (oclusão) e perfil facial

A relação molar $\mathrm{Cl} \mid$ foi a mais freqüente nos dois grupos, não havendo diferença significativa entre ambos. Em um paciente com AIJ não foi possível determinar a relação molar, devido a ausência de molares e caninos.

No grupo com AlJ, 21(60\%) pacientes tinham perfil reto, $12(34,2 \%)$ tinham perfil convexo e dois $(5,7 \%)$ tinham perfil côncavo. Houve diferença significativa em relação ao grupo controle $(p=0,002)$.

Todos os dados podem ser observados na Tabela 5. 
Tabela 5. Distribuição dos grupos quanto à relação molar e ao perfil facial

\begin{tabular}{|c|c|c|c|}
\hline & $\begin{array}{c}\text { AIJ }(n=35) \\
N(\%)\end{array}$ & $\begin{array}{l}\text { Controle }(n=35) \\
\qquad N(\%)\end{array}$ & $\begin{array}{c}\mathrm{p} \\
\text { (Fischer) }\end{array}$ \\
\hline Relação molar & & & 0,452 \\
\hline $\mathrm{Cll}$ & $21(60)$ & $22(62,8)$ & \\
\hline $\mathrm{Cl} I \mathrm{I}$ & $11(31,4)$ & $8(22,8)$ & \\
\hline $\mathrm{Cl} I I I$ & $2(5,7)$ & $5(14,2)$ & \\
\hline Perfil & & & 0,002 \\
\hline Reto & $21(60)$ & $30(85,7)$ & \\
\hline Côncavo & $2(5,7)$ & $4(11,4)$ & \\
\hline Convexo & $12(34,2)$ & $1(2,8)$ & \\
\hline
\end{tabular}

Mordida aberta anterior

Na Tabela 6 são apresentados os dados referentes à mordida aberta e suas relações com outras variáveis. Quanto às alterações radiográficas destes pacientes, todos os pacientes com AlJ apresentaram alteração condilar grau 2 ou 3 (dois apresentaram alteração condilar grau 2 e três apresentaram alteração condilar grau 3). No grupo controle, sete pacientes com mordida aberta anterior possuíam radiografia panorâmica, sendo que nenhum deles apresentou alteração condilar grau 3 e apenas duas avaliações foram coincidentes considerando os examinadores 1, 3 e 4, com um paciente apresentando alteração condilar grau 1 e um paciente com alteração condilar grau 2. 
Tabela 6: Distribuição dos grupos quanto à presença de mordida aberta anterior

\begin{tabular}{ccc}
\hline Dados & AlJ $(n=5)$ & Controle $(n=9)$ \\
\hline Idade média \pm dp ( variação) & $10 \pm 2,05$ & $9,6 \pm 2,37$ \\
& $(8$ a 13 anos $)$ & $(7$ a 15 anos $)$
\end{tabular}

Sexo

\begin{tabular}{|c|c|c|}
\hline \multirow[t]{2}{*}{$\begin{array}{c}\text { Feminino } \\
\text { Masculino } \\
\text { Tipo de início }\end{array}$} & $\begin{array}{c}3 \\
2 \\
4 \text { sistêmico }\end{array}$ & $\begin{array}{l}6 \\
3\end{array}$ \\
\hline & 1 oligo estendido & \\
\hline Tempo de doença $\pm d p$ (variação) & $7,4 \pm 1,51$ (6 a 9 anos) & \\
\hline Idade de início \pm dp (variação) & $3,8 \pm 2,95$ ( 2 a 9 anos $)$ & \\
\hline Perfil & & \\
\hline Reto & 2 & 8 \\
\hline Convexo & 3 & 0 \\
\hline Côncavo & 0 & 1 \\
\hline Relação molar & & \\
\hline $\mathrm{Cl}$ & 3 & 3 \\
\hline Cll & 1 & 3 \\
\hline $\mathrm{CIII}$ & 1 & 3 \\
\hline Presença de queixas & 3 & 3 \\
\hline Índice de disfunção clínica & & \\
\hline grave & 3 & 0 \\
\hline moderado & 1 & 1 \\
\hline leve & 1 & 6 \\
\hline normal & 0 & 2 \\
\hline Índice de mobilidade mandibular & & \\
\hline grave & 4 & 0 \\
\hline leve & 1 & 4 \\
\hline normal & 0 & 5 \\
\hline Ruídos presentes & 1 crepitação & 1 estalo \\
\hline $\begin{array}{l}\text { Avaliações Radiográficas } \\
\text { coincidentes }\end{array}$ & 5 & 2 \\
\hline Grau 1 & 0 & 1 \\
\hline Grau 2 & 2 & 1 \\
\hline Grau 3 & 3 & 0 \\
\hline
\end{tabular}


Condição dentária e gengival

A Tabela 7 mostra os dados relacionados aos índices CPO-D, de placa e de sangramento gengival. Esses índices, em valores absolutos foram maiores no grupo AIJ, porém sem diferenças estatisticamente significativas. A avaliação de dentes perdidos mostrou diferença significativa do grupo AIJ em relação ao grupo controle $(p=0,025)$.

Tabela 7: Distribuição dos grupos quanto às características dentárias e gengivais

\begin{tabular}{|c|c|c|c|}
\hline Índices & $\begin{array}{c}\text { AlJ } \\
(n=35)\end{array}$ & $\begin{array}{l}\text { Controle } \\
(n=35)\end{array}$ & $\begin{array}{c}\mathrm{p} \\
\text { (Mann-Whitney) }\end{array}$ \\
\hline CPO-D & $5,3 \pm 4,75$ & $3.4 \pm 2,92$ & 0,790 \\
\hline C & $1,8 \pm 2,20$ & $1,8 \pm 2,17$ & 0,903 \\
\hline $\mathrm{P}$ & $1 \pm 1,66$ & $0,2 \pm 0,40$ & 0,025 \\
\hline $\mathrm{O}$ & $2,4 \pm 3,03$ & $1,4 \pm 1,61$ & 0,206 \\
\hline IP & $54,5 \pm 32,63$ & $43,3 \pm 24,19$ & 0,171 \\
\hline IS & $21,6 \pm 19,2$ & $18,7 \pm 14,69$ & 0,818 \\
\hline
\end{tabular}

$\mathrm{Na}$ Tabela 8 pode-se observar que houve aumento progressivo nos índices CPO-D, de placa e de sangramento gengival no grupo com AIJ, à medida que aumentou o número de articulações de membros superiores comprometidas pela doença. Os pacientes com AlJ que possuem de 3 a 8 
articulações de membros superiores afetadas diferem significativamente do grupo controle em relação ao CPO-D $(p=0,036)$.

Tabela 8: Distribuição dos doentes com AIJ de acordo com o número de articulações comprometidas dos membros superiores e sua relação com os índices de saúde oral, comparativamente ao grupo controle

\begin{tabular}{|c|c|c|c|c|}
\hline Índices & $\begin{array}{c}\text { AlJ } \\
0 \text { a } 2 \underset{(n=17)}{\text { articulações }} \\
(n=17\end{array}$ & $\begin{array}{c}\text { AlJ } \\
3 \text { a } 8 \text { articulações } \\
(n=18)\end{array}$ & $\begin{array}{l}\text { Controle } \\
(n=35)\end{array}$ & $\begin{array}{c}\mathrm{p} \\
\text { (Mann- Whitney) }\end{array}$ \\
\hline CPO-D & $3,9 \pm 2,92$ & $6,7 \pm 5,76$ & $3,42 \pm 2,92$ & 0,036 \\
\hline IP & $45,7 \pm 28,78$ & $62,6 \pm 34,68$ & $43,3 \pm 24,19$ & 0,058 \\
\hline IS & $15,1 \pm 12,36$ & $27,7 \pm 22,69$ & $18,7 \pm 14,69$ & 0,260 \\
\hline
\end{tabular}

\section{Disfunção mandibular}

Na Tabela 9 pode-se observar diferença estatisticamente significativa do Índice de Disfunção Clínica de Helkimo no grupo AlJ $(p=0,003)$, comparativamente ao grupo controle. Dez pacientes com AlJ (28,5\%) apresentaram Índice de Disfunção Clínica grave $(p=0,001)$. O Índice de Mobilidade Mandibular também foi significativo estatisticamente entre os dois grupos $(p=0,001)$, sendo que o grupo AlJ apresentou também maior gravidade $(p=0,001)$. 
Tabela 9. Distribuição dos grupos quanto aos Índices de Helkimo (Disfunção Clínica e Mobilidade Mandibular)

\begin{tabular}{|c|c|c|c|}
\hline Índices & $\begin{array}{c}\text { AlJ }(n=35) \\
N(\%)\end{array}$ & $\begin{array}{c}\text { Controle }(n=35) \\
N(\%)\end{array}$ & $\begin{array}{c}\text { p } \\
\text { (Qui- } \\
\text { quadrado) }\end{array}$ \\
\hline Disfunção & $33(94,2)$ & $23(65,7)$ & 0,003 \\
\hline Grave & $10(28,5)$ & $0(0)$ & \\
\hline Moderada & $5(14,2)$ & $5(14,2)$ & \\
\hline Leve & $18(51,4)$ & $18(51,4)$ & 0,001 \\
\hline Sem disfunção & $2(5,7)$ & $12(34,2)$ & \\
\hline Mobilidade diminuída & $28(80)$ & $14(40)$ & 0,001 \\
\hline Gravemente & $12(34,2)$ & $0(0)$ & \\
\hline Levemente & $16(45,7)$ & $14(40)$ & 0,001 \\
\hline Sem comprometimento & $6(17,1)$ & $21(60)$ & \\
\hline
\end{tabular}

Já na Tabela 10 são mostrados os dados referentes aos movimentos mandibulares, cuja amplitude de abertura de boca no grupo AlJ foi estatisticamente menor que no grupo controle $(p<0,001)$. Da mesma forma, as excursões médias das lateralidades e da protusão mandibular foram estatisticamente menores no grupo AlJ ( $p=0,003, p<0,001$ e $p<0,001)$, respectivamente à direita, à esquerda e à protrusão. 
Tabela 10: Amplitude dos movimentos mandibulares dos pacientes com AIJ, comparativamente aos controles

\begin{tabular}{lccc}
\multicolumn{1}{c}{ Movimentos } & AlJ & Controle & $\begin{array}{c}p \\
\text { (t de Student) }\end{array}$ \\
\hline Abertura de boca & $38,6 \pm 7,39 \mathrm{~mm}$ & $48,4 \pm 4,62 \mathrm{~mm}$ & $<0,001$ \\
Lateralidade direita & $8,0 \pm 2,77 \mathrm{~mm}$ & $9,7 \pm 1,61 \mathrm{~mm}$ & 0,003 \\
Lateralidade esquerda & $7,2 \pm 2,87 \mathrm{~mm}$ & $9,6 \pm 1,60 \mathrm{~mm}$ & $<0,001$ \\
Protrusão & $4,5 \pm 2,37 \mathrm{~mm}$ & $7,2 \pm 2,35 \mathrm{~mm}$ & $<0,001$ \\
\hline
\end{tabular}

Quanto a prevalência de dor à palpação muscular e/ou articular, 27 (77,1\%) pacientes com AlJ apresentaram dor, contra 15 (42,8\%) do grupo controle, diferença estatisticamente significante $(p=0,003)$. No grupo AlJ a presença da dor mista (articular mais muscular) foi estatisticamente superior à dor apenas articular ou muscular $(p=0,001)$. Os dados estão apresentados na Tabela 11

Tabela 11: Distribuição dos grupos quanto à presença de dor nos músculos da mastigação (muscular), na articulação temporomandibular (ATM) ou em ambos (dor mista)

\begin{tabular}{|c|c|c|c|}
\hline Dor à Palpação & $\begin{array}{c}\text { AIJ }(n=35) \\
N(\%)\end{array}$ & $\begin{array}{c}\text { Controle }(\mathrm{n}=35) \\
\mathrm{N}(\%)\end{array}$ & $\begin{array}{c}p \\
\text { (Qui-quadrado) }\end{array}$ \\
\hline Presente & $27(77,1)$ & $15(42,8)$ & 0,003 \\
\hline Muscular & $14(40)$ & $14(40)$ & \\
\hline ATM & $0(0)$ & $0(0)$ & 0,001 \\
\hline Mista & $13(37,1)$ & $1(2,8)$ & \\
\hline Sem dor & $8(22,8)$ & $20(57,1)$ & \\
\hline
\end{tabular}


Relacionando idade de início e o tempo de duração da doença com características odontológicas, houve diferença estatisticamente significativa quando se comparou a idade de início da doença com o tipo de perfil encontrado, sendo que o perfil facial convexo relacionou-se com idades menores de início da AlJ $(p=0,010)$. Todos os dados destas comparações são apresentados na Tabela 12.

Tabela 12: Distribuição dos doentes com AlJ relacionando o tipo de perfil facial e os Índices de Disfunção de Helkimo com a idade de início e o tempo de duração da AlJ

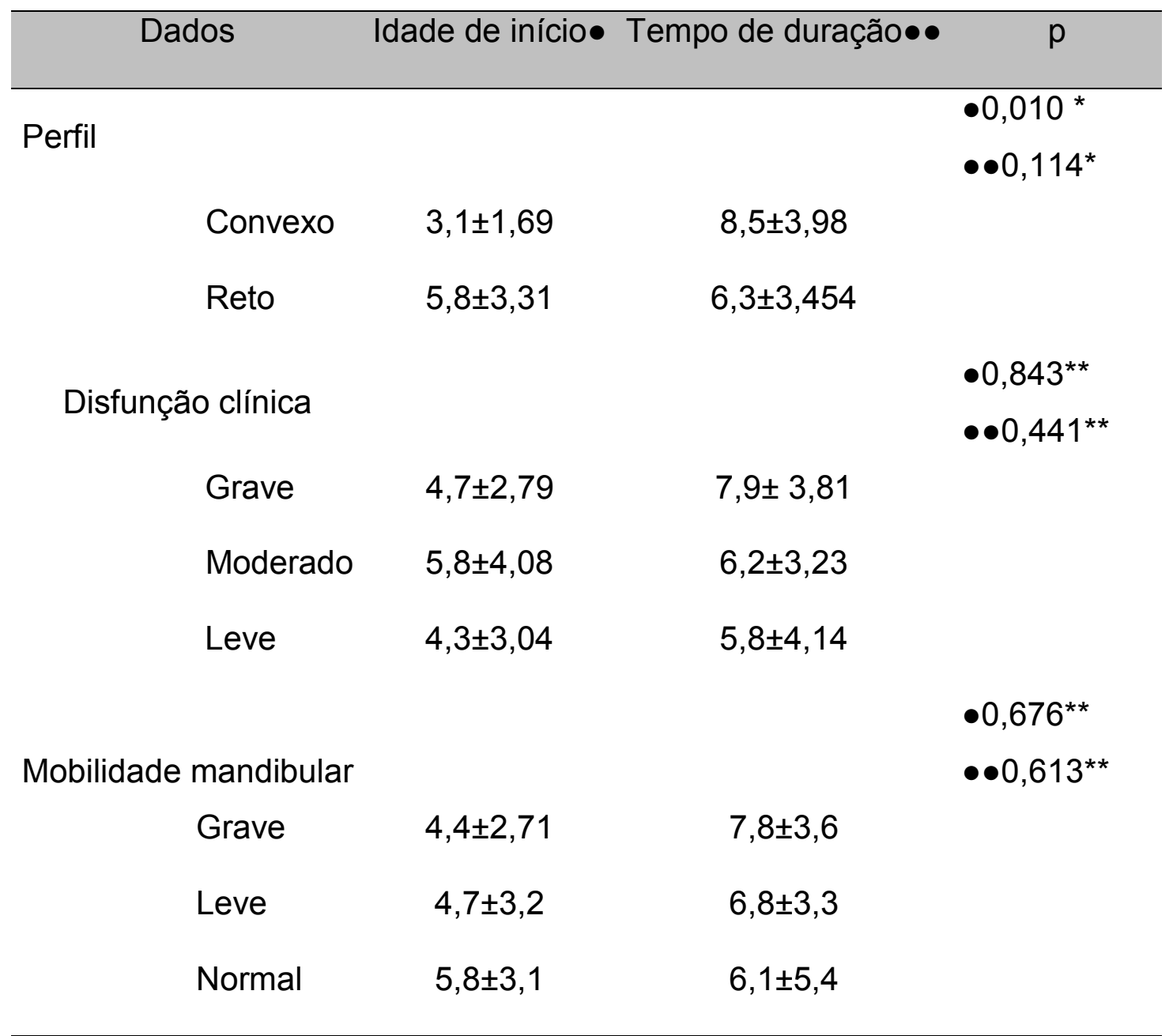

- relativo à idade de início da AIJ; ••relativo ao tempo de duração da AlJ

* Teste de Mann - Whitney; ${ }^{* *}$ Teste de Kruskal-Wallis 
Ruídos articulares da ATM

Houve diferença significativa entre os dois grupos quanto à presença de ruídos na ATM $(p=0,040)$. A crepitação ocorreu em $75 \%$ dos pacientes com AlJ. Tabela 13.

Tabela 13: Distribuição dos grupos quanto à presença de ruídos na ATM

\begin{tabular}{lccc}
\multicolumn{1}{c}{ Ruídos } & AIJ $(\mathrm{n}=35)$ & Controle $(\mathrm{n}=35)$ & $\mathrm{p}$ \\
& $\mathrm{N}(\%)$ & $\mathrm{N}(\%)$ & (Qui-quadrado) \\
\hline Ausentes & $27(77,1)$ & $33(94,2)$ & 0,040 \\
Presentes & $8(22,8)$ & $2(5,7)$ & \\
\hline
\end{tabular}

\section{Alterações Radiográficas}

Houve retorno da radiografia panorâmica de face por $27(77,1 \%)$ pacientes do grupo AIJ e por $24(68,5 \%)$ do grupo controle. Os pacientes deram diferentes justificativas para a ausência do exame após repetidas solicitações. As alterações radiográficas condilares, avaliadas por quatro examinadores independentes, são apresentadas na Tabela 14. 
Tabela 14: Distribuição dos grupos quanto ao grau de alteração radiográfica condilar realizado por 4 examinadores independentes

\begin{tabular}{|c|c|c|c|c|c|c|c|c|}
\hline \multirow{3}{*}{ 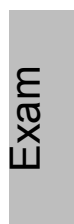 } & \multicolumn{2}{|c|}{ Grau 0} & \multicolumn{2}{|c|}{ Grau 1} & \multicolumn{2}{|c|}{ Grau 2} & \multicolumn{2}{|c|}{ Grau 3} \\
\hline & $\begin{array}{c}\text { AlJ } \\
(n=27)\end{array}$ & $\begin{array}{c}\text { Controle } \\
(n=24)\end{array}$ & $\begin{array}{c}\text { AlJ } \\
(n=27)\end{array}$ & $\begin{array}{c}\text { Controle } \\
(n=24)\end{array}$ & $\begin{array}{c}\mathrm{AlJ} \\
(\mathrm{n}=27)\end{array}$ & $\begin{array}{c}\text { Controle } \\
(n=24)\end{array}$ & $\begin{array}{c}\text { AlJ } \\
(n=27)\end{array}$ & $\begin{array}{c}\text { Controle } \\
(n=24)\end{array}$ \\
\hline & N (\%) & N (\%) & N (\%) & $\mathrm{N}(\%)$ & $N(\%)$ & $N(\%)$ & $N(\%)$ & $N(\%)$ \\
\hline 1 & $5(18,5)$ & $10(4,1)$ & $4(14,8)$ & $9(37,5)$ & $11(40,7)$ & $5(20,8)$ & $7(30)$ & $0(0)$ \\
\hline 2 & $9(33,3)$ & $20(83,3)$ & $4(14,8)$ & $3(12,5)$ & $6(22,2)$ & $1(4,1)$ & $8(29,6)$ & $0(0)$ \\
\hline 3 & $5(18,5)$ & $6(25)$ & $6(22,2)$ & $12(50)$ & $12(44,4)$ & $6(25)$ & $4(14,8)$ & $0(0)$ \\
\hline 4 & $3(11,1)$ & $1(4,1)$ & $5(18,5)$ & $12(50)$ & $13(48,1)$ & $0(41,6)$ & $5(18,5)$ & $1(4,1)$ \\
\hline
\end{tabular}

Exam - examinador

Quanto à concordância entre 2 de 4 examinadores das radiografias panorâmicas, a Tabela 15 mostra que no grupo AlJ houve boa concordância entre os examinadores 1 e 4 (índice kappa = 0,68).

Tabela 15: Distribuição dos grupos quanto à concordância entre 2 de 4 examinadores sobre a presença de alterações condilares nas radiografias panorâmicas

\begin{tabular}{lcccc}
\hline Examinadores & \multicolumn{2}{c}{ AlJ } & \multicolumn{2}{c}{ Controle } \\
& Kappa & Concordância & Kappa & Concordância \\
\hline 1 e 2 & 0,46 & aceitável & 0,38 & regular \\
1 e 3 & 0,33 & regular & 0,11 & fraca \\
1 e 4 & 0,68 & boa & 0,24 & regular \\
2 e 3 & 0,22 & regular & 0,18 & fraca \\
2 e 4 & 0,43 & aceitável & 0,02 & fraca \\
3 e 4 & 0,41 & aceitável & 0,08 & fraca \\
\hline
\end{tabular}


Quanto à concordância entre 3 de 4 examinadores das radiografias panorâmicas, a Tabela 16 mostra concordância melhor para o grupo AIJ $(48,1 \%)$ e para o grupo controle $(25,0 \%)$ pelos examinadores 1,3 e 4 . Estes dados podem ser observados na Tabela 16.

Tabela 16: Distribuição dos grupos quanto à coincidência entre os examinadores sobre a presença de alterações condilares nas radiografias panorâmicas

\begin{tabular}{lcc}
\hline \multicolumn{1}{c}{ Examinadores } & $\begin{array}{c}\mathrm{AlJ}(\mathrm{n}=27) \\
\mathrm{N}(\%)\end{array}$ & $\begin{array}{c}\text { Controle }(\mathrm{n}=24) \\
\mathrm{N}(\%)\end{array}$ \\
\hline Todos & $9(33,3)$ & $2(8,3)$ \\
$1,2,3$ & $9(33,3)$ & $6(25)$ \\
$1,3,4$ & $13(48,1)$ & $6(25)$ \\
$2,3,4$ & $10(37)$ & $2(8,3)$ \\
$1,2,4$ & $13(48,1)$ & $3(12,5)$ \\
\hline
\end{tabular}

Na Tabela 17 são mostrados os dados sobre os graus de alteração radiográfica condilar e a coincidência entre 3 de 4 examinadores. Os examinadores 1, 3 e 4 tiveram mais coincidências no grupo AlJ: duas $(7,4 \%)$ de grau 0 , uma $(3,7 \%)$ de grau 1 , sete $(25,9 \%)$ de grau 2 e três $(11,1 \%)$ de grau 3. No grupo controle as melhores coincidências foram: $5(20,8 \%)$ de grau 1 e uma $(4,1 \%)$ de grau 2. Houve maior coincidência entre os examinadores 1, 3 e 4 para as alterações radiográficas condilares de grau 1 no grupo controle e de grau 2 para o grupo AIJ, havendo diferença 
estatisticamente significante entre os grupos $(p=0,01)$. De $13(48,1 \%)$ avaliações coincidentes entre os examinadores 1 , 3 e 4 em 10 delas (76\%) a alteração condilar foi grau 2 ou 3.

Tabela 17: Distribuição dos grupos quanto ao grau de alterações radiográficas condilares por 3 de 4 examinadores

\begin{tabular}{ccccccccccc}
\hline \multicolumn{4}{c}{ Grau 0 } & \multicolumn{2}{c}{ Grau 1 } & \multicolumn{2}{c}{ Grau 2 } & \multicolumn{2}{c}{ Grau 3 } & \\
Exam & AIJ & Controle & AlJ & Controle & AIJ & Controle & AlJ & Controle & $p$ \\
& $(n=27)$ & $(n=24)$ & $(n=27)$ & $(n=24)$ & $(n=27)$ & $(n=24)$ & $(n=27)$ & $(n=24)$ & $($ Fischer $)$ \\
& $N(\%)$ & $N(\%)$ & $N(\%)$ & $N(\%)$ & $N(\%)$ & $N(\%)$ & $N(\%)$ & $N(\%)$ & \\
\hline Todos & $2(7,4)$ & $0(0)$ & $1(3,7)$ & $1(4,1)$ & $3(11,1)$ & $0(0)$ & $3(11,1)$ & $0(0)$ & \\
$1,2,3$ & $2(7,4)$ & $3(12,5)$ & $1(3,7)$ & $1(4,1)$ & $3(11,1)$ & $0(0)$ & $3(11,1)$ & $0(0)$ & \\
$1,3,4$ & $2(7,4)$ & $0(0)$ & $1(3,7)$ & $5(20,8)$ & $7(25,9)$ & $1(4,1)$ & $3(11,1)$ & $0(0)$ & 0,01 \\
$2,3,4$ & $2(7,4)$ & $0(0)$ & $1(3,7)$ & $1(4,1)$ & $4(14,8)$ & $0(0)$ & $3(11,1)$ & $0(0)$ & \\
$1,2,4$ & $4(14,8)$ & $1(4,1)$ & $1(3,7)$ & $1(4,1)$ & $3(11,1)$ & $1(4,1)$ & $5(18,5)$ & $0(0)$ & \\
\hline
\end{tabular}

Exam - examinadores

Agrupando as alterações radiográficas condilares em apenas 2 graus de comprometimento (0-1 e 2-3), verifica-se entre os examinadores 1 , 3 e 4 coincidência em 14 (52\%) pacientes do grupo AlJ para alterações condilares grau 2-3, com diferença estatisticamente significante $(p=0,04)$ em relação ao respectivo grupo controle. Ver a Tabela 18. 
Tabela 18: Distribuição dos grupos quanto à presença de alterações radiográficas condilares subdivididas em 2 graus de comprometimento

\begin{tabular}{lccccc}
\hline Examinadores & \multicolumn{2}{c}{ AlJ $(\mathrm{n}=27)$} & \multicolumn{2}{c}{ Controle $(\mathrm{n}=24)$} & $\mathrm{p}$ \\
$\mathrm{N}(\%)$ & $\mathrm{N}(\%)$ & $\mathrm{N}(\%)$ & $\mathrm{N}(\%)$ & \\
\hline Todos & $6(22,2)$ & $13(48,1)$ & $11(45,8)$ & $0(0)$ & \\
$1,2,3$ & $7(25,9)$ & $13(48,1)$ & $15(62,5)$ & $0(0)$ & \\
$1,3,4$ & $6(22,2)$ & $14(51,8)$ & $11(45,8)$ & $2(8,3)$ & 0,04 \\
$2,3,4$ & $7925,9)$ & $13(48,1)$ & $11(45,8)$ & $0(0)$ & \\
$1,2,4$ & $7(25,9)$ & $13(48,1)$ & $13(54,1)$ & $1(4,1)$ & \\
\hline
\end{tabular}




\section{DISCUSSÃO}

Embora $94,2 \%$ das crianças com AlJ apresentassem sinais clínicos de DTM, elas não tinham queixas importantes de dor na região orofacial. No entanto, quando questionadas, $28,5 \%$ referiram dor na face, ou nos dentes, ou à função mandibular. Como a dor na ATM tem pouco impacto na vida desses doentes, pois é menos sintomática em comparação às outras articulações do corpo, e por raramente impedir a completa função mandibular ${ }^{8,34}$, nem sempre ela está incluída nas queixas primárias dos pacientes com AIJ. Dessa forma, as alterações da AIJ na ATM acabam sendo subdiagnosticadas, principalmente nos estágios iniciais da doença, e suas complicações faciais ou na ATM acabam sendo percebidas tardiamente, quando são visíveis as deficiências estruturais e ou funcionais mandibulares ${ }^{34,67,94}$. Neste estudo, em apenas cinco doentes com AlJ $(14,2 \%)$ foi identificado o envolvimento da ATM ao exame médico inicial. Sem dúvida, o exame odontológico precoce de crianças com AIJ pode auxiliar na identificação do acometimento dessa articulação, mas é de suma importância que o médico inclua no seu protocolo de avaliação de doentes com AlJ o exame mais apurado da ATM. Assim, o diagnóstico precoce da AIJ na ATM permitiria adoção de medidas que poderiam minimizar os efeitos da doença na função mandibular e no crescimento facial da criança.

A prevalência de sinais e sintomas de DTM nos pacientes do grupo controle foi similar às descritas na literatura ${ }^{53}$ e neste estudo houve um alto 
índice de disfunção clínica e de comprometimento da mobilidade mandibular em pacientes com AIJ, confirmando o envolvimento da ATM nestes pacientes. Esta maior freqüência de DTM nos pacientes com AlJ é justificada pela gravidade da amostra, na qual $62,8 \%$ dos pacientes têm início da doença sistêmico, todos eles têm evolução poliarticular, início precoce da doença e longa duração; fatores que aumentam o risco para a ATM e a gravidade das lesões inflamatórias $5,8,9,61,65,76,93$.

Dor à palpação da ATM foi encontrada em $37,1 \%$ dos pacientes com AIJ, sendo que todos esses pacientes apresentaram concomitantemente dor à palpação dos músculos mastigatórios, que normalmente são afetados secundariamente a lesões articulares. Por outro lado, a presença exclusiva de dor à palpação dos músculos mastigatórios (40\%) foi similar entre os pacientes com AlJ e controle, e compatíveis à prevalência desse sintoma na população geral (47 a 68\%) ${ }^{53,54}$. Harper, $200{ }^{34}$, com o objetivo de determinar a relação entre DTM, dor e desempenho mastigatório em crianças com AlJ, observou prejuízo mastigatório nas crianças com AlJ que apresentavam DTM, e atribui estes resultados possivelmente a mecanismos de evitação de dor, com prejuízo da função.

Prejuízo funcional da ATM, nesta amostra, é evidenciado pela restrição de mobilidade mandibular presente em $80 \%$ dos pacientes com AIJ, valores também compatíveis aos descritos na literatura ${ }^{94,98}$. Todos os movimentos mandibulares foram reduzidos nos pacientes com AIJ e, especificamente, a limitação de abertura de boca, o que impede o movimento final de translação do côndilo mandibular, e justificaria a presença de ruídos articulares em 
apenas $22,8 \%$ dos $51,8 \%$ pacientes com AlJ que apresentaram alterações radiográficas condilares moderadas a graves (Grau 2-3).

Pacientes com AlJ podem apresentar diminuição do crescimento mandibular, resultando em alterações faciais como perfil convexo, micrognatia, retrognatia e mordida aberta anterior $4,5,55,59,63,70,73,74,78,79$. Perfil convexo é um aspecto físico importante em crianças com AlJ, e 34,2\% dos pacientes avaliados apresentaram esta condição. Este tipo de perfil comumente está associado à doença avançada da ATM, onde já ocorreu reabsorção parcial dos côndilos mandibulares, além de outras alterações faciais decorrentes dessa doença articular degenerativa.

A mordida aberta anterior foi mais prevalente nos pacientes do grupo controle, porém nestes pacientes não foi possível associá-la a nenhuma outra alteração facial, ou anormalidade radiográfica, ou até mesmo a sintomas de disfunção mandibular, como foi observado nos pacientes com AIJ, que nitidamente compunham um grupo diferente em relação a esse aspecto. Três pacientes com AlJ apresentaram alteração facial e perfil convexo, e, apesar da cautela na análise desta associação, pois os próprios tecidos moles da face podem mimetizar esta condição, todos os pacientes com AIJ apresentavam alteração condilar grau 2-3, ao passo que no grupo controle, apesar da pouca concordância entre os examinadores, nenhum paciente apresentou alteração radiográfica condilar grave. No grupo com AlJ todos os pacientes apresentaram algum grau de disfunção mandibular, sendo que três deles apresentaram disfunção grave, além do que a mobilidade mandibular gravemente comprometida foi observada em quatro 
pacientes desse grupo. No grupo controle, a disfunção mandibular leve esteve presente em seis pacientes e a mobilidade mandibular levemente comprometida em outros quatro pacientes. Assim, é provável que no grupo com AIJ a mordida aberta anterior decorra de complicações na ATM pela AIJ e no grupo controle esteja associada a outros fatores.

A falta de concordância entre os examinadores, sobre as alterações radiográficas condilares, mostra claramente as dificuldades de avaliar o côndilo mandibular, particularmente das crianças do grupo controle, que não apresentaram alterações degenerativas graves. Além disso, essas crianças estão em fase de crescimento e podem existir variações anatômicas próprias desse período. O índice kappa de melhor concordância entre 2 de 4 examinadores foi apenas razoável para o grupo controle, enquanto houve um bom para o grupo AIJ. A concordância piora quando se reúnem 3 de 4 examinadores independentes, pois no grupo controle nenhum percentual de concordância foi superior a $25 \%$, diferente do grupo AIJ, que mesmo tendo baixa concordância, atingiu $48,1 \%$. Por outro lado esses dados reforçam o fato de que as alterações da ATM pela AIJ são diferentes e podem ser identificadas se houver treinamento adequado, pois aproximadamente $52 \%$ dos pacientes com AIJ apresentaram alteração radiográfica condilar graus 2 ou 3.

A radiografia panorâmica, apesar de ser um exame de pouca precisão, permite ampla visualização do esqueleto facial, incluindo as ATMs, e é

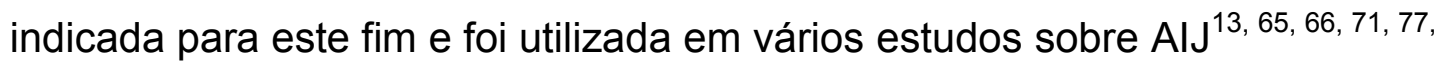
94. Estes autores concordam que como primeiro exame, desde que avaliado 
por olhos experientes, a radiografia panorâmica é fundamental, pois, além de outras vantagens, permite boa visão dos côndilos mandibulares. Sem dúvida, outros exames como a tomografia computadorizada e a ressonância nuclear magnética dão detalhes adicionais indispensáveis sobre os tecidos duros e moles da ATM e permitem a detecção de alterações precoces nessa articulação $6,86,98,101$. As vantagens da radiografia panorâmica como baixo custo, baixa radiação e fácil execução ${ }^{98}$, aliada à necessidade de exames radiográficos de rotina nos pacientes com AlJ, uma vez que as alterações radiográficas precedem os sintomas clínicos $^{8}$, tornam este exame o de eleição para avaliação destes pacientes ${ }^{2}$. O uso desta radiografia como primeiro exame facilita os controles periódicos dos pacientes.

Queixas de dor dental podem não resultar da AlJ, mas sim em conseqüência de suas seqüelas, como limitações físicas dos pacientes, principalmente quando estão presentes prejuízo funcional das articulações de membros superiores ${ }^{10,11,18,103,104,105}$. No nosso estudo, os índices de cárie, de placa e de sangramento gengival aumentaram progressivamente à medida que aumentou o número de articulações de membros superiores comprometidas, sendo o índice CPO-D diferente do controle quando a AIJ acometeu de 3-8 articulações de membros superiores e o índice de placa apresentou tendência de diferença entre os grupos.

Crianças com AlJ não conseguem realizar higiene oral adequada e isto pode resultar em pior condição bucal. O maior número de dentes perdidos nestas crianças, quando comparados ao controle, sugere que apresentam maior gravidade de doenças dentárias. Não se deve esquecer a condição 
social das crianças desta amostra e a própria dificuldade de acesso a tratamentos dentários, considerando que o setor público tem limitações e normalmente está sobrecarregado. É possível também que o tratamento dentário não seja considerado uma prioridade para essas crianças, ou por seus pais, e até mesmo pelos dentistas, nem sempre treinados nesse sentido, quer para o diagnóstico complementar sobre AIJ na ATM, quer para avaliação das eventuais complicações dentárias e ou periodontais que nelas ocorrem, ou mesmo pela dificuldade de acesso à cavidade oral ${ }^{11,12,60}$.

Quando AIJ é diagnosticada pelos médicos, torna-se indispensável orientá-las e encorajá-las a manter uma boa saúde oral. Os pais e cuidadores também deveriam ser treinados para ajudá-las na realização da higiene oral. Orientações de dieta, particularmente em relação a ingestão de açúcar, e consultas odontológicas periódicas ajudariam no manejo de condições dentárias associadas ${ }^{12,60}$. Esta estratégia reduziria o risco de doenças infecciosas, como cárie e doença periodontal, as quais são potencialmente de risco, particularmente nas infecções buco-dentais agudas, à atividade da doença.

Nossos dados reforçam a necessidade de investigação padronizada não somente da ATM, mas também de dentes, gengiva e características faciais em pacientes com AlJ. Futuros estudos controlados poderão ajudar a definir melhor o envolvimento da ATM e estabelecer procedimentos dentários preventivos. Mais visitas ao dentista pode ser necessário a estas crianças. 0 conhecimento das alterações dentárias e da ATM resultante da AIJ, bem como avaliação precoce do sistema mastigatório das crianças com esta 
doença, é necessário para identificar estes pacientes. Estes estudos buscam o estabelecimento de planos de tratamento que minimizem a morbidade orofacial potencial associada a esta doença, contribuindo para a melhora da qualidade de vida destas crianças. 


\section{CONCLUSÕES}

1. A prevalência de doenças dentárias e periodontais foi maior nos pacientes com AlJ, aumentando progressivamente a medida que aumenta o número de articulações de membros superiores acometidas pela doença;

2. A prevalência de sinais e sintomas de disfunção mandibular foi maior nos pacientes com AIJ, com redução da amplitude de movimentos mandibulares nestes pacientes;

3. As características oclusais foram semelhantes entre os dois grupos;

4. Perfil facial convexo foi mais prevalente nos pacientes com AlJ;

5. Ao exame radiográfico, alterações na ATM foram mais freqüentes em pacientes com AlJ;

6. A idade de início da doença de pacientes com AlJ que apresentavam perfil convexo foi significativamente menor que a dos pacientes que apresentavam perfil reto. 
8. Anexos

Anexo 1 
a) Avaliação clínica médica

1. Nome:

2. RGHC:

3. Idade:

4. Sexo:

5. Forma de início:

( ) Pauciarticular ( ) Poliarticular

( ) Sistêmica.

6. Forma de evolução:

) Pauciarticular ( ) Poliarticular

( ) Sistêmica.

7. Tempo da doença:

8. Curso da doença:

( ) Monocíclico ( ) Policíclico

( ) Contínuo

9. Classe funcional:

( ) I

( ) II

( ) III

( ) IV

10.Medicamentos: ( )AINH ( )Corticosteróide ( )Drogas de base

11. Articulações comprometidas:

12. Articulações ativas:

13. Laboratório: $\mathrm{Hmg}\{\mathrm{Hb}$ : Ht: leucócitos: plaquetas:

VHS:

EFP:

14. Outras doenças: 
b) Ficha Clínica

1. Queixa principal / duração:

2. Localização da dor:

3. Fator inicial:

4. Tratamentos realizados para a dor:

5. Tipo de dor: ( )pontada ( )peso ( ) queimor ( ) choque ( ) latejante ( )cansaço ( )outros

6.. É espontânea?

7.. Frequência da dor:( ) diária ( ) dias alternados ( ) quinzenal ( ) mensal ( ) esporádica

8. Período de piora: ( ) manhã ( ) tarde ( ) noite ( ) indiferente

9. Intensidade da dor: ( ) fraca ( ) moderada ( ) forte Nota:

10. Consegue localizar a dor:

11. Fatores de acalmia: ( ) frio ( ) calor ( ) medicamento ( ) outros 12. Fatores de piora: ( ) frio ( ) calor ( ) doce ( ) tensão emocional

$$
\text { ( ) mastigação ( ) fala ( ) bocejo ( ) outros }
$$

13. Sente o rosto cansado?

14. Mastigação é: ( ) D ( ) E ( ) bilateral ( ) a frente

15. Tem otalgia?

16. Tem cefaléia? 
Anexo 4

c) Avaliação Periodontal

1. Índice de placa: $\underline{n} .^{\circ}$ de superfícies coradas $\times 100=$ $\%$

n. ${ }^{\circ}$ de dentes $\times 4$

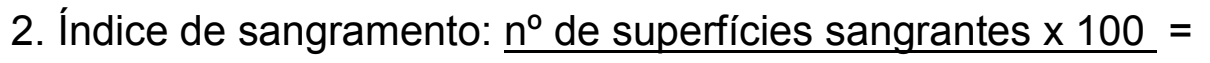
$\%$ $n^{\circ}$ de dentes $\times 4$ 
Anexo 5

d) Avaliação dentária:

1. Índice CPO-D:

CPO-D $=C+P+O$

$\mathrm{C}=$ dentes cariados

$\mathrm{P}=$ dentes perdidos

$\mathrm{O}=$ dentes obturados

2. Tipo de oclusão: ( ) Cl I Angle

( ) Cl II Angle

( ) Cl III Angle

3. Perfil : ( ) côncavo ( ) convexo ( ) reto 
e) Avaliação articular

1.Índice de Helkimo

- Índice de disfunção clínica

- Sintoma: Comprometimento do índice de mobilidade mandibular Critério: Movimentos normais

Ligeiro comprometimento do movimento 1

Grave comprometimento do movimento 5

- Sintoma: Comprometimento funcional da ATM

Critério:Movimento suave, sem ruído articular e desvio em AB e Fec $<2 \mathrm{~mm} \_0$ Ruído articular uni ou bilateral e/ou desvio $>2 \mathrm{~mm}$ na $\mathrm{AB}$ ou Fec $\_1$ Travamento ou luxação da ATM 5

- Sintoma: Dor muscular

Critério: Sem dor a palpação muscular 0

Dor em 1-3 locais 1

Dor em quatro ou mais locais 5

- Sintoma: Dor em ATM

Critério: Sem dor à palpação 0

Dor à palpação lateral 1

Dor à palpação posterior 5

- Sintoma: Dor em movimentos mandibulares

Critério: Sem dor 0 
Dor em 1 movimento 1

Dor em 2 ou mais movimentos 5

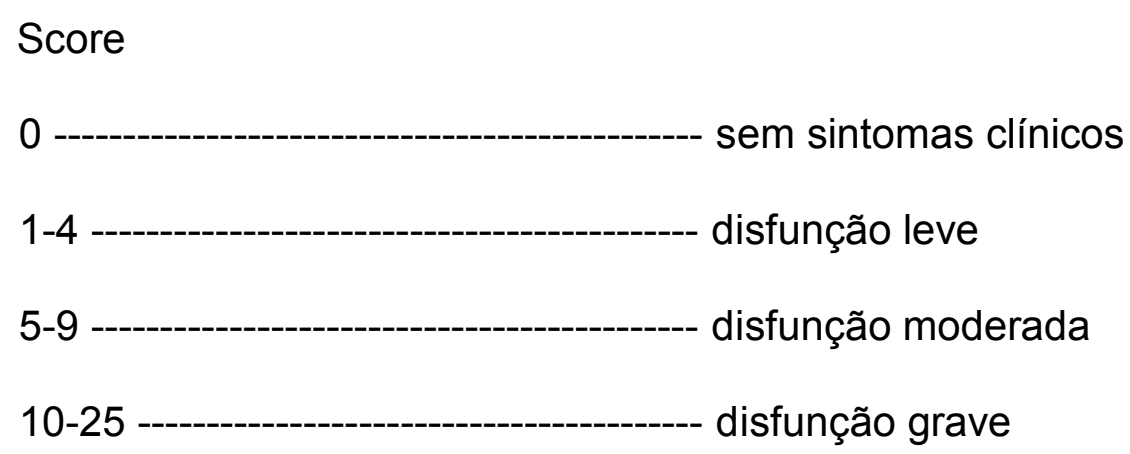

- Índice de mobilidade mandibular

- Abertura bucal máxima de $\mathrm{mm}$

$>40 \mathrm{~mm}$ 0 30-39 mm 1 $<30 \mathrm{~mm}$ 5

- Máximo movimento de lateralidade $D$ de $\mathrm{mm}$

$>7 \mathrm{~mm}$ 0

4-6 mm 1

0-3 mm 5

- Máximo movimento de lateralidade $\mathrm{E}$ de $\mathrm{mm}$ 
$>7 \mathrm{~mm}$

4-6 mm 1

0-3 mm 5

- Máxima protrusão de $\mathrm{mm}$

$>7 \mathrm{~mm}$ 0

4-7 mm 1

0-3 mm 5

Score

0 mobilidade mandibular normal

$1-4$ mobilidade ligeiramente comprometida

$5-20$ -mobilidade gravemente comprometida 
f) Avaliação radiográfica: radiografia panorâmica

1. Forma dos côndilos e dos ramos mandibulares;

( ) Grau 0: sem anormalidades radiográficas

Superfície óssea articular do côndilo com contornos convexos e bem definido

( ) Grau 1: Anormalidade leve

Defeitos na borda condilar, erosões menores.

( ) Grau 2: Anormalidade moderada

Aplainamento do côndilo.

( ) Grau 3: Anormalidade grave

Destruição total do côndilo

2. Avaliação dos dentes, periodonto e osso alveolar. 


\section{REFERÊNCIAS BIBLIOGRÁFICAS}

1. Cassidy JT, Petty RE - Juvenile rheumatoid arthritis. In: Cassidy JT, Petty RE. Textbook of Pediatric Rheumatology. 4rd ed. Philadelphia: B. Saunders Co; 2001. p. 218-322.

2. Twilt M, Mobers SMLM, Arends LR, Cate R, Suijlekom-Smit LWA. Temporomandibular involvement in juvenile idiopathic arthritis. $J$ Rheumatol. 2004; 31:1418-22.

3. Stabrun AE, Larheim TA, Höyeraal HM, Rösler M. Reduced mandibular dimensions and asymmetry in juvenile rheumatoid arthritis. Arthritis and Rheumatism. 1988; 31: 602-11.

4. Stabrun AE. Impaired mandibular growth and micrognathic development in children with juvenile rheumatoid arthritis. A longitudinal study of lateral cephalographs. Eur J Orthodontics. 1991; 13: 423-34.

5. Ronchezel MV, Hilário MOE, Goldenberg J, Lederman HM, Faltin K Jr, Azevedo MF, Naspitz CK. Temporomandibular joint and mandibular growth alterations in patients with juvenile rheumatoid arthritis. $J$ Rheumatol.1995; 22:1956-61.

6. Hu Y-S, Schneiderman ED. The temporomandibular joint in juvenile rheumatoid arthritis: I. Computed tomographic findings. Pediatric dentistry. $1995 ; 17: 46-53$. 
7. Hanna VE, Rider SF, Moore TL, Wilson VK, Osborn TG, Rotskoff KS Johnston Jr LE. Effects of Systemic Onset Juvenile Rheumatoid Arthritis on Facial Morphology and Temporomandibular Joint Form and Function. $J$ Rheumatol.1996; 23:155-8.

8. Grosfeld $\mathrm{O}$. The orthodontist in the team-treatment for children with rheumatoid arthritis. Eur J of Orthodontics. 1989;11:120-4.

9. Viola MJ, Barbosa RLL, Hilário MOE, Faltin JrK. Avaliação Ortodôntica Clínica e Cefalométrica em Pacientes com Artrite Reumatóide Juvenil. Ortodontia. 1996; 29:71-80.

10. Tanchyk AP. Dental considerations for the patient with juvenile rheumatoid arthritis. General Dentistry. 1991; Sept/oct: 300-32.

11. Walton AG, Welbury RR, Foster HE, Thomason JM. Juvenile chronic arthritis: a dental review. Oral Diseases. 1999; 5: 68-75.

12. Welbury RR, Thomason JM, Fitzgerald JL, Steen IN, Marshall NJ, Foster HE. Increased prevalence of dental caries and poor oral hygiene in juvenile idiopathic arthritis. Rheumatology. 2003; 42: 1445-51.

13. Pedersen TK, Jensen JJ, Melsen B, Herlin T. Resorption of the temporomandibular condylar bone according to subtypes of juvenile chronic arthritis. J Rheumatol. 2001; 28:2109-15.

14. Espinel $\mathrm{CH}$. “Caravaggio's ïl amore dormiente": A sleeping cupid with juvenile rheumatoid arthritis. Lancet. 1994; 344:1750-2.

15. Oliveira SKF. Artrite Idiopática Juvenil: Histórico, Epidemiologia e Etiopatogenia. In: Oliveira SKF, Azevedo ECL. Reumatologia Pediátrica. 2a ed. Rio de Janeiro: Ed Revintel; 2001. p.145-52. 
16. Brewer EJ, Giannini EH, Person DA. Artrite Reumatóide Juvenil. 2a ed. São Paulo: Manoele; 1984.

17. Weldt LL, Aguilera MM, Loyola MT. Artrite Idiopática Juvenil: Nomenclatura e Classificação. In: Oliveira SKF, Azevedo ECL. Reumatologia Pediátrica. 2a ed. Rio de Janeiro: Ed Revintel; 2001. p.143-5.

18.. Ansell BM. Juvenile chronic arthritis. Scand J Rheumatol, 1987;66 (Suppl):47-50, 1987

19. Cassidy JT, Levinson JE, Bass, JC, Baum J, Brewer EJ, Fink CW, Hanson V, Jacobs JC, Masi AT, Schaller JG, Fries JF, Mcshane D, Young D. A study of classification criteria for a diagnosis of juvenile rheumatoid arthritis. Arthritis Rheum. 1986;29:274-81.

20. Cassidy JT, Petty RE .The Juvenile idiopathic arthritides. In: Cassidy JT, Petty RE. Textbook of Pediatric Rheumatology. 4rd ed. Philadelphia: B. Saunders Co; 2001. p. 214-7.

21. Petty RE, Southwood TR, Manners P, Baum J, Glass DN, Goldenberg J et al. International League of Associations for Rheumatology classification of juvenile idiopathic arthritis: second revision, Edmonton, 2001. J Rheumatol 2004; 31:390-2

22. Petty RE, Southwood TR, Baum J, Bhettay E, Glass DN, Manners P, Maldonado-Cocco J, Suarez-Almazor M, Orozco-Alcala J, Prieur AM Revision of the proposed classification criteria for juvenile idiopathic arthritis: Durban 1997. J Rheumatol . 1998;25(11):1991-1994. 
23. Oliveira SKF. Artrite Idiopática Juvenil: características dos diferentes subtipos. In: Oliveira SKF, Azevedo ECL. Reumatologia Pediátrica. 2a ed. Rio de Janeiro: Ed Revintel; 2001. p.152-68.

24. Warren RW, Perez MD, Curry MR, Wilking AP, Myones BL. Juvenile Idiopathic Arthritis. In: Koopman WJ. Arthritis and Allied conditions. 14 th ed. Philadelphia: Lippincott Willians \& Wilkins; 2001.p.1270-93.

25. Schaller JG. Chronic childhood arthritis and spondylarthropathies. In: Colin A. Spondylarthropathies. Orlando: Grune and Stratton Inc; 1984. p.187-208.

26. Gare BA, Fasth A. A epidemiology of juvenile chronic rheumatoid arthritis in southwestern Sweden: a 5-year prospective population study. Pediatrics. 1992; 90:950-8.

27. Cassidy JT, Petty RE. Juvenile rheumatoid arthritis. In: Cassidy JT, Petty RE. Textbook of rheumatology. 3rd ed. New York: Churchill, Livingstone; 1995, p.133-223.

28. Kiss MHB. Estudo sobre determinação de um índice prognóstico em crianças portadoras de artrite reumatóide juvenil [tese livre-docência]. São Paulo: Faculdade de Medicina, Universidade de São Paulo; 1994.

29. Andrade LEC. Etiopatogenia. In: Moreira C, Carvalho MAP. Reumatologia: Diagnóstico e Tratamento. 2a ed. Rio de janeiro: Ed Médica e Científica;2001. p.29-45.

30. Zide MF, Carlton DM, Kent JN. Rheumatoid disease and related arthropathies. Oral Surg Oral Med Oral Pathol. 1986; 61: 119-25. 
31. Silva CAA. Caracterização da forma sistêmica da ARJ em 80 pacientes. [dissertação]. São Paulo: Faculdade de Medicina, Universidade de São Paulo; 1997.

32. Lovell DJ, White PH. Growth and nutrition in juvenile rheumatoid arthritis. In: Woo P, White PH, Ansell, BM. Pediatric Rheumatology update. Oxford: Oxford University Press; 1990. p.47-56.

33. Woo PMM. Growth retardation and osteoporosis in juvenile chronic arthritis. Clin. Exp. Rheumatol. 1994;12 (supl10): 87-90.

34. Harper RP, Brown CM, Triplett MM, Villasenor A, Gatchel RJ. Masticatory function in patients with juvenile rheumatoid arthritis. Pediatr Dent. 2000;22(3): 200-6.

35. Oliveira SKF. Exames complementares. In: Oliveira SKF, Azevedo ECL. Reumatologia Pediátrica. 2a ed. Rio de Janeiro: Ed Revintel; 2001. p.173-82.

36. Giannini EH, Petty RE. Treatment of Juvenile Rheumatoid Arthritis. In: Koopman WJ. Arthritis and Allied conditions. 14 th ed. Philadelphia: Lippincott Willians \& Wilkins; 2001.p.1294-310

37. Oliveira SKF. Tratamento. In: Oliveira SKF, Azevedo ECL. Reumatologia Pediátrica. 2a ed. Rio de Janeiro: Ed Revintel; 2001. p.183-201.

38. Fink CW. Overview of corticosteroid therapy in the different rheumatic diseases of childhood. Clin Exp Rheumatol. 1991;9 (Suppl 6):9-13.

39. Melo-Gomes JA. Problems related to systemic glucocorticoid therapy in children. J Rheumatol. 1993;20 (Supl 37):35-9. 
40. Rosemberg AM. Advanced drug therapy for juvenile rheumatoid arthritis. J Pediatr. 1989; 114:171-7.

41. Solberg WK. Disfunções e desordens temporomandibulares. Tradução de WS Gomes. São Paulo: Liv Santos; 1989.

42. König JrB. Morfologia funcional da ATM. In: Tratamento das Disfunções Craniomandibulares/ATM. São Paulo: JJ Barros \& SM Rode. Livraria Santos; 1995. p. 27-34.

43. Navarro JAC. Anatomia cirúrgica da ATM. In: Tratamento das disfunções craniomandibulares/ATM. São Paulo. JJ Barros e SM Rode. Livraria Santos; 1995. p. 43-59.

44. Siqueira JTT. Dor articular - anormalidades da ATM. In: Siqueira JTT, Teixeira MJ. Diagnóstico, terapêutica e qualidade de vida. Curitiba:Ed Maio; 2001.p. 447-76.

45. Katchburian E, Arana V. Articulação temporomandibular. In: Katchburian E, Arana V. Histologia e Embriologia Oral. São Paulo: Panamericana; 1999. p.356-73.

46. Kopp S. Degenerative and inflammatory temporomandibular joint disorders: clinical perspectives. IN: Sessle BJ, Bryant PS, Dionne RA. Temporomandibular disorders and related pain conditions. Progress in Pain Research and management. Seattle: IASP Press; 1995.p.199-31.

47. Siqueira JTT, Camparis C, Savioli C. Disfunção temporomandibular: conceito, classificação, aspectos fisiopatológicos e clínicos. In: Teixeira MJ. Dor: contexto interdisciplinar. Curitiba: Ed Maio; 2003. p. 429-42. 
48. Pullinger AG, Siligman DA, Gornbern JA. A multiple regresson analysis of the risk and relative odds of temporomandibular disorders as function of common oclusal features. J Dent Res. 1993; 72: 68-79.

49. .Vanderas AP. Synergistic effect of malocclusion and oral parafunctions on craniomandibular dysfunction in children with and without unpleasant life events. Journal of Oral Rehabilitation 1996; 23: 61-5.

50. Vanderas AP. Craniomandibular dysfunction in children: part V. Correspondence between signs and symptoms. J Dent Child. 1992; set/out: 342-5.

51. Siqueira JTT, Ching LH. Dor Orofacial/ATM Bases para o Diagnóstico Clínico. Curitiba: Ed Maio, 1999.

52. Kosminsky M, Góes PSA. Epidemiologia da dor orofacial: tipos de dores mais prevalentes. In: Teixeira MJ. Dor: contexto interdisciplinar. Curitiba: Ed Maio; 2003. p. 75-88.

53. List $\mathrm{T}$, Wahlund $\mathrm{K}$, Wenneberg $\mathrm{B}$, Dworkin SF. TMD in children and adolescents: prevalence of pain, gender differences, and perceived treatment need. J Orofac Pain. 1999;13:9-20.

54. Vanderas AP. Prevalence of craniomandibular dysfunction in white children with different emotional states. Part II: not calm group. J Dent Child. 1989; set/out: 340-52.

55. Kjellberg H. Craniofacial growth in juvenile chronic arthritis. Acta Odontol Scand. 1998; 56:360-5.

56. Shafer WG, Hine MK, Levy BM. Tratado de Patologia Bucal. $4^{\text {a }}$ ed. Rio de janeiro: Guanabara; 1987. Cap.7, p. : Cárie Dentária. 
57. Vellini FF. Ortodontia - Diagnóstico e Planejamento Clínico. São Paulo: Ed. Artes Médicas;1997.

58. Lindhe J. Tratado de Periodontia Clínica e Implantologia Oral. 3a ed. Rio de Janeiro, Guanabara; 1999. p.

59. Rönning O, Barnes SAR, Pearson MH, Pledger DM. Juvenile chronic arthritis: a cephalometric analysis of the facial skeleton. Eur J Orthod. 1994; 16: 53-62.

60. Bazan MT. An Overview of Juvenile Rheumatoid Arthritis. The Journal of Pedodontics. 1981; Fall: 68-76.

61. Hu Y-S, Schneiderman ED, Harper RP. The temporomandibular joint in juvenile rheumatoid arthrits: II. Relationship between computed tomographic and clinical findings. Pediatric dentistry. 1996; 18:312-9.

62. Kjellberg H, Kiliards S, Karlsson S. Characteristics of Masticatory Movements and Velocity in Children with Juvenile Chronic Arthritis. $J$ Orofacial Pain. 1995; 9:64-72.

63. Sidiropoulou-Chatzigianni S, Papadopoulos MA, Kolokithas G. Dentoskeletal morphology in children with juvenile idiopathic arthritis compared with healthy children. J Orthod. 2001; 28: 53-8.

64. Tavakkoli Jou MR, Miller AJ, Kapila S. Mandibulofacial adaptations in a juvenile animal model of temporomandibular joint arthritis. $J$ Dent Res. 1999;78: 1426-35.

65. Larheim TA, Höyeraal HM, Stabrun AE, Haanaes HR. The temporomandibular joint in juvenile rheumatoid arthritis. Scand $J$ Rheumatology. 1982; 11:5-12. 
66. Pearson MH, Rönning E. Lesions of the Mandibular Condyle in Juvenile Chronic Arthritis. British Journal of Orthodontics. 1996; 23:49-56.

67. Kreiborg S, Bakke M, Kirkeby S, Michler L, Vedtofte P, Seidler B, Moller E. Facial Growth and oral function in a case of juvenile rheumatoid arthritis during an 8 year period. Eur J Orthod. 1990;12: 119-34.

68. Pedersen TK, Gronhoj J, Melsen B, Herlin T. Condylar condition and mandibular growth during early functional treatment of children with juvenile chronic arthritis. Eur J Orthod. 1995; 17:385-94.

69. Grosfeld O, Czarnecka K, Drecka-Kuzan W, Szymanska-Jagiello, Zyszko A. Clinical investigation of the temporomandibular joint in children and adolescents with rheumatoid arthritis. Scand J Rheumatology. 1973; 2: 145-9.

70. Kjellberg H, Kiliaridis S, Thilander B. Dentofacial growth in orthodontically treated and untreated children with juvenile chronic arthritis (JCA). A comparision with Angle Cl II division 1 subjects. Eur J Orthod. 1995; 17 : 357-73.

71. Larheim TA. Radiographic appearance of the normal temporomandibular joint in newborns and small children. Acta Radiological Diagnosis. 1981; 22:593-9.

72. Mericle PM, Wilson VK, Moore TL, Hanna VE, Osborn TG, Rotskoff KS, Johnston LE. Effects of polyarticular and pauciarticular onset juvenile rheumatoid arthritis on facial and mandibular growth. J Rheumatol. 1996; 33: 159-65. 
73. Zifer SA, Sams DR, Potter BJ, Jerath R. Clinical and radiographic evaluation of juvenile rheumatoid arthritis: report of a case. Spec Care Dentist. 1994; 14:208-11.

74. Stabrun AE. Mandibular morphology and position in juvenile rheumatoid arthritis. A study on postero-anterior radiographs. Eur J Orthod. 1985; 7:288-98.

75. Fahel, ALS. Alterações mandibulares em pacientes portadores de artrite reumatóide juvenil.[Dissertação]. São Paulo. Escola Paulista de Medicina, Universidade Federal de São Paulo; 2003.

76. Stabrun AE, Larheim TA, Höyeraal HM. Temporomandibular Joint Involvement in Juvenile Rheumatoid Arthritis. Scand J Rheumatology. 1989;18: 197-204.

77. Kjellberg H, Ekestubbe A, Kiliaridis S, Thilander B. Condylar heigth on panoramic radiographs. A methodologic study with a clinical application. Acta Odontol Scand. 1994; 52:43-50.

78. Savioli C, Silva CAA, Siqueira JTT. Características morfológicas e funcionais do sistema estomatognático em pacientes portadores de artrite reumatóide juvenil. JBO. 2000;4:70-78.

79. Kjellberg H, Fasth A, Kiliaridis S, Wenneberg B, Thilander B. Craniofacial structure in children with juvenile chronic arthritis (JCA) compared with healthy children with ideal or postnormal occlusion. Am J Orthod Dentof Ortop. 1995; 107:67-78. 
80. Mayro RF, Delozier JB. Facial reconstruction consideration in rheumatic disease. Rheumatic Disease Clinics of North America. 1991; 17: 943953.

81. Guyuron B. Facial Deformity of Juvenile Rheumatoid Arthritis. Plastic and Reconstructive Surgery. 1988, 81: 948-51.

82. Turpin DL. Juvenile rheumatoid arthritis: a 14-year posttreatment evaluation. Angle orthodontist. 1989; 59: 233-8.

83. Svensson B, Adell R. Costochondral grafts to replace mandibular condyles in juvenile chronic arthritis patients: long-term effects on facial growth. J Craniomaxillofac Surg. 1998; 26:275-85.

84. Svensson B, Feldmann G, Rindler A. Early surgical-orthodontic treatment of mandibular hypoplasia in juvenile chronic arthritis. J Craniomaxillofac Surg. 1993; 21: 67-75.

85. Simões WA. An orthodontic challenge. Juvenile rheumatoid arthritis: examination protocol. World J Orthod. 2001; 2: 56-68.

86. Kitai N, Kreiborg S, Bake M, Paulsen HU, Moller E, Darvann TA, Pedersen $\mathrm{H}$, Takada $\mathrm{K}$. Three dimensional resonance image of the mandible and masticatory muscles in a case of juvenile chronic arthritis treated with the Herbst appliance. Angle orthod. 2002; 72: 81-7.

87. Maggioncalda EA. Treatment of a class II, division 1 vertical growth pattern with severe anterior crowding. Am $J$ Orthod Dentof Orthop. 1997; 112: 300-8. 
88. Marini I, Vecchiet F, Spiazzi L, Capurso U. Stomatognathic function in juvenile rheumatoid arthritis and in developmental open-bite subjects. $J$ Dent Child. 1999; 66:30-5.

89. Proffit WR. Treatment Planning: the search for wisdom. In:Proffit WR, White RPJr. Surgical orthodontic treatment. St Louis: Mosby-Year Book; 1991. p. 159.

90. Martini G, Bacciliero U, Tregnaghi A, Montesco MC, Zulian F. Isolated temporomandibular synovitis as unique presentation of juvenile idiopathic arthritis. J Rheumatol. 2001; 28:1689-92.

91. Olson L, Echerdal O, Hallonsten AL, Helkimo M, Koch G, Gäre A. Craniomandibular function in juvenile chronic arthritis: a clinical and radiographic study. Sweed Dent J. 1991; 15: 71-83.

92. Tanchyk A. treating growth and TMJ abnormalities in juvenile rheumatoid arthritis. JADA. 1994; 125: 1617-21.

93. Bakke M, Zak M, Jensen BL, Pedersen FK, Kreiborg S. Orofacial pain, jaw function, and temporomandibular disorders in women with a history of juvenile chronic arthritis ou persistent juvenile chronic arthritis. Oral Surg Oral Med Oral Pathol Oral Radiol Endod. 2001; 92:406-14.

94. Wenneberg B, Kjellberg H, Kiliaridis S. Bite force and temporomandibular disorder in juvenile chronic arthritis. Journal of Oral Rehabilitation. 1995; 22:633-41.

95. Svensson B, Larsson A, Adell R. The mandibular condyle in juvenile chronic arthritis patients with mandibular hypoplasia. A clinical and histological study. Int J Oral Maxillofac Surg. 2001; 30:306-312. 
96. Block RM, Matteson SR, Rosof M, Mendlinger N, Reiskin AB. The evaluation of a typical facial pain in a patient with rheumatoid disease and its sequaelae. J Conn State Dent Assoc. 1975; 49: 249-55.

97. Savioli C, Silva CAA, Siqueira JTT. Artrite reumatóide juvenil. In: Siqueira JTT, Teixeira MJ. Dor orofacial: diagnóstico, terapêutica e qualidade de vida. Curitiba: Ed Maio; 2001.p. 477-87.

98. Kitai N, Kreiborg S, Murakami S, Bake M, Moller E, Darvann TA, Takada K. A three dimensional method of visualizing the temporomandibular joint based on magnetic resonance imaging in a case of juvenile chronic arthritis. Int J Paediatr Dent. 2002; 12: 109-15.

99. Martis CS, Karakasis DT. Ankylosis of the temporomandibular joint caused by Still's disease. Oral Surg. 1973;35:462-6.

100. Galantier C, Siqueira JTT. O uso de radiografias panorâmicas no diagnóstico da dor orofacial. In: Siqueira, JTT, Ching, LH. Dor Orofacial/ATM - Bases para o Diagnóstico Clínico. Curitiba. Ed Maio; 1999. p. .

101.Avrahami E, Segal R, Solomon A, Garti A, Horowitz I, Caspi D, Wiggler I, Yaron M. Direct Coronal High Resolution Computed Tomography of the temporomandibular joints in patients with rheumatoid arthritis. $J$ Rheumatol. 1989;16:198-301.

102. Kapila S, Lee C, Tavakkoli Jou MR, Miller AJ, Richards DW. Development and histologic characterization of an animal model of antigen-induced arthritis of the juvenile rabbit temporomandibular joint. J Dent Res. 1995; 74: 1870-79. 
103. Siamopoulou A, Mavridis AK, Vasakos S, Benecos P, Tzioufas AG, Andonopoulos AP. Sialochemistry in Juvenile Chronic Arthritis. British Journal Rheumatology. 1989; 28:383-5.

104. Foster H. Rheumatoid arthritis and children [letter]. JADA. 1999; 130: 1694-5.

105. Burden D, Mullally B, Sandler J. Orthodontic treatment of patients with medical disoders. Eur J Orthod. 2001, 23: 363-72.

106. Oksa LA, Helenius $H$, Rönning $O$. Advanced dental maturity in children with juvenile rheumatoid arthritis. Eur J Oral Sci. 2000; 108: 184-8.

107. Steinbrocker $\mathrm{O}$, Traeger $\mathrm{CH}$, Batterman $\mathrm{RC}$. Therapeutic criteria in rheumatoid arthritis. JAMA 1949;140:650-662.

108. Siqueira JTT. Disfunção temporomandibular: classificação e abordagem clínica. In: Siqueira JTT, Teixeira MJ. Dor orofacial: diagnóstico, terapêutica e qualidade de vida. Curitiba: Ed Maio; 2001.p. 374-404.

109. Ainamo J, Bay I. Problems and proposals for recording gingivitis and plaque. International Dental Journal 1975; 25:229-235.

110. O'Leary TJ - The periodontal screening examination. Journal of Periodontology 1967; 38:617-624.

111. World Health Organization - Oral health surveys: basic methods. 4th ed; 1997; Geneva.

112. Helkimo $\mathrm{H}$ - Studies on function and dysfunction of the masticatory system. II. Index for anamnestic dysfunction and occlusal state. Swed Dent J. 1974; 67:101-119. 